University of Texas at El Paso

\title{
DigitalCommons@UTEP
}

Open Access Theses \& Dissertations

2018-01-01

\section{Investigating the 2016 Jackson, Wyoming Earthquake Sequence Using Waveform Cross- Correlation and Seismic Array Methods}

Emily Jo Graves

University of Texas at El Paso, egraves1@lssu.edu

Follow this and additional works at: https://digitalcommons.utep.edu/open_etd

Part of the Geophysics and Seismology Commons

\section{Recommended Citation}

Graves, Emily Jo, "Investigating the 2016 Jackson, Wyoming Earthquake Sequence Using Waveform Cross-Correlation and Seismic Array Methods" (2018). Open Access Theses \& Dissertations. 78.

https://digitalcommons.utep.edu/open_etd/78 


\section{INVESTIGATING THE 2016 JACKSON, WYOMING EARTHQUAKE SEQUENCE USING WAVEFORM CROSS-CORRELATION \\ AND SEISMIC ARRAY METHODS}

\section{EMILY JO GRAVES}

Master's Program in Geophysics

APPROVED:

Diane I. Doser, Ph.D., Chair

Marianne S. Karplus, Ph.D.

Charlotte A. Rowe, Ph.D.

Charles Ambler, Ph.D.

Dean of the Graduate School 
Copyright (C)

by

Emily Jo Graves

2018 


\section{Dedication}

This thesis is dedicated to my family and my closest friends who have shown unwavering support during many months of research and writing. 
INVESTIGATING THE 2016 JACKSON, WYOMING EARTHQUAKE SEQUENCE USING WAVEFORM CROSS-CORRELATION

AND SEISMIC ARRAY METHODS

by

EMILY JO GRAVES, B.S.

THESIS

Presented to the Faculty of the Graduate School of

The University of Texas at El Paso

in Partial Fulfillment

of the Requirements

for the Degree of

MASTER OF SCIENCE

Department of Geological Sciences

THE UNIVERSITY OF TEXAS AT EL PASO

December 2018 


\section{Acknowledgements}

I would like to thank Dr. Diane Doser for her support and guidance while pursuing this thesis project. As well as, Dr. Charlotte Rowe for providing the opportunity to work at Los Alamos National Laboratory under her supervision. I would also like to thank the many others who have made this thesis possible: Richard Stead, Annette Veilleux, Mike Begnaud, and Marianne Karplus. 


\begin{abstract}
An energetic seismic sequence was detected by the Montana Bureau of Mines and Geology (MBMG) in August 2016, near Jackson, Wyoming. The sequence was also recorded at the Pinedale Seismic Array (PDAR) located to the southeast of the regional and local networks used by the MBMG to locate the seismic events. The catalog locations were validated, and earthquake location integrity was investigated in the absence of a well-distributed network through the implementation of array processing methods to the seismic sequence recorded at PDAR.
\end{abstract}

During a visual inspection of PDAR data extracted for the catalog events, I observed additional, unreported events, which is to be expected during an energetic swarm or seismic sequence. The casual observation of missed events strongly implied that more such missed events could be found in the data, which could improve the completeness of the earthquake catalog for the Jackson, Wyoming area. Catalog completeness improves our assessment of a region's tectonic behavior and earthquake exposure. To search for recurring swarm or earthquake sequence behavior, I applied waveform correlation methods to scan nearly two decades of continuous PDAR waveforms, comparing to template events selected from the "Jackson Swarm" catalog, to identify repeating events from the source area of the swarm.

The array processing methods explored in this study were able to determine earthquake locations using PDAR with an average accuracy of nearly $11 \mathrm{~km}$. These errors are permissible in studies to determine areas of seismological interest and the identification of regions impacted by mining explosions and nuclear testing.

Two unreported events were identified using from the cross-correlation scan, dismissing the possibility of previous swarm behavior, and indicating a main shock - aftershock sequence. 


\section{Table of Contents}

Dedication _ 3

Acknowledgements__ V

Abstract__ vi

Table of Contents __ vii

List of Tables __ viii

List of Figures _

1. Introduction _ 1

2. Regional Geology and Geologic History ___ 4

2.1 Regional Deformation___ 4

2.2 Wind River Range___ 5

2.3 Green River Basin _ 7

2.4 Gros Ventre Range ___ 9

2.5 Hoback Basin _ 12

3. Methodology __ 14

3.1 Data Collection __ 14

3.2 Earthquake Location Verification Utilizing a Network ___ 14

3.3 Earthquake Location Utilizing Seismic Array Processing ___ 18

3.3.1 Picking P and S Wave Arrivals __ 18

3.3.2 Beam Forming _ـ 18

3.3.3 F-K Analysis — 22

$\begin{array}{ll}\text { 3.3.4 Distance Determinations } & 27\end{array}$

3.3.5 Latitude and Longitude Calculations___ 30

3.4 Cross-Correlation Swarm Reoccurrence Scan ___ 31

4. Results and Discussion __ 34

4.1 Seismic Array Locations___ 34

4.2 Cross-Correlation Swarm Reoccurrence Scan __ 44

5. Conclusions__ 48

References__ 49

Appendix _ 53

Curriculum Vita _ 65 


\section{List of Tables}

Table 3.2.1: Draney Peak Velocity Model

Table A1: Earthquake Information

Table A2: Hypoinverse Command File

Table A3: P Wave and S Wave Signal to Noise Ratios 59

Table A4: BBFK Results Part 1

Table A5: BBFK Results Part 2 


\section{List of Figures}

Figure 1.1: Regional Map __ 1

Figure 2.1: Regional Geology ___ 4

Figure 2.2: The Wind River Range___ 6

Figure 2.3: The Green River Basin___ 8

Figure 2.4: The Gros Ventre Range 10

Figure 2.5: Southeastern Deformation __ 12

Figure 2.6: The Hoback Basin __ 13

Figure 3.1.1: PDAR Components__ 14

Figure 3.2.1: Network Station Locations __ 16

Figure 3.3.1: Back Azimuth __ 20

Figure 3.3.2: The F-K Diagram __ 24

Figure 3.3.3: FFT Plots __ 26

Figure 3.3.4: Cosine 29

Figure 4.1.1: Network Location Validation __ 34

Figure 4.1.2: Average Velocity Method Locations ___ 35

Figure 4.1.3: Wavenumber Method Locations ___ 36

Figure 4.1.4: Magnitude vs Epicentral Error from Average Velocity Method__ 37

Figure 4.1.5: Signal to Noise Ratio vs Epicentral Error from Average Velocity Method __ 38

Figure 4.1.6: Back Azimuth vs Epicentral Error from Average Velocity Method____ 39

Figure 4.1.7: Earthquake Locations in the Gros Ventre Region___ 40

Figure 4.1.8: Fault Identification Map __ 41

Figure 4.1.9: Moment Tensor _ـ 42

Figure 4.1.10: Event Magnitudes Map ___ 43

Figure 4.1.11: Event Migration Map — 44

Figure 4.2.1: Template 1 Cross-Correlation Results __ 45

Figure 4.2.2: Template 2 Cross-Correlation Results 46

Figure 4.2.3: Event Magnitudes Over Epoch Time _ 47 


\section{Introduction}

In August 2016, a seismic sequence began near Jackson, Wyoming. The sequence was recorded by the Montana Bureau of Mines and Geology (MBMG) and at the Pinedale Seismic Array (PDAR). PDAR is operated by the Air Force Technical Applications Center and is located southeast of the regional and local networks used by the MBMG (Figure 1.1).

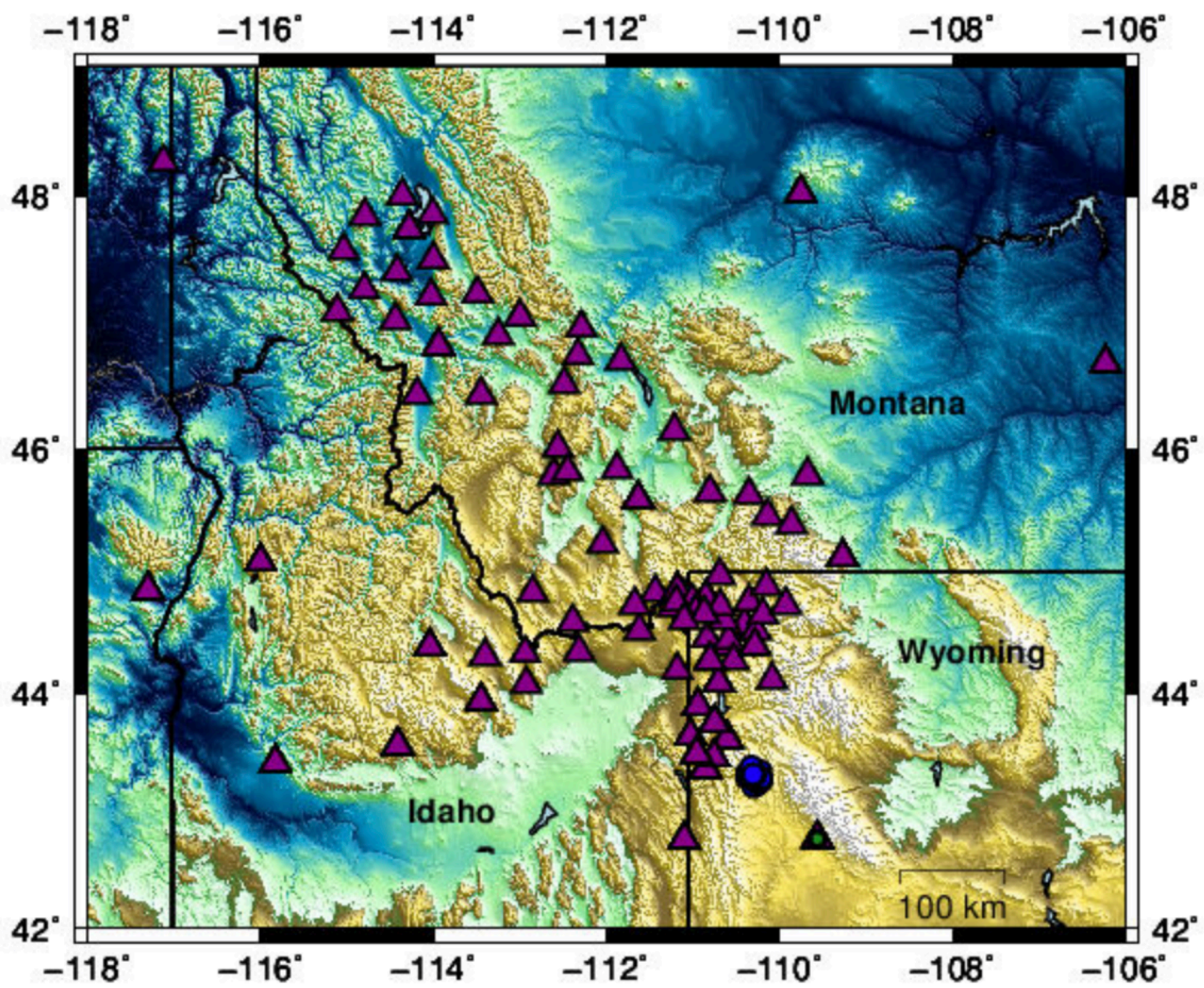

Figure 1.1: Regional Map

The local and regional network stations used by the Montana Bureau of Mines and Geology are shown by magenta triangles. The blue circles represent the locations of the seismic sequence events. The Pinedale Array location is shown as a green triangle. 
The seismic sequence started on August $23^{\text {rd }}, 2016$ and continued till November $16^{\text {th }}$. Comprised of 58 events ranging in magnitude from 5.2 ML to $0.9 \mathrm{ML}$, the majority of events are below magnitude $2 \mathrm{ML}$. The event epicenters are $\sim 80 \mathrm{~km}$ from the PDAR location. Using the sequence recorded at PDAR, I investigate earthquake location integrity in the absence of a welldistributed network, e.g. MBMG, through the application of array processing methods.

Since the 1960's, seismic arrays have been designed to detect earthquakes and discriminate these events from nuclear explosions (Rost and Thomas 2002). Many seismic arrays have been designed to detect teleseismic events in the interest of national security, but little work has been done to improve near array event detection. Accurately locating earthquakes or anthropogenic events close to an array has many applications. These include induced seismicity studies, hazard mitigation, nuclear test ban treaty monitoring, and an economical way to record seismic data from inaccessible places.

The seismic sequence has been called the "Jackson Swarm" but little work has been done to distinguish the nature of the series of earthquakes. Determining if the series of earthquakes is a seismic sequence or a seismic swarm provides clues to the regional geology and local tectonics. Landslides have been associated with swarm events and understanding possible swarm migration along the regional faults might assist in forecasting regions more likely to shift and result in a landslide.

During visual inspection of PDAR data for the catalog events, we observed additional, unreported events. The casual observation of missed events strongly implies that more such missed events can be found in the data, which could improve completeness of the earthquake catalog for the Jackson, Wyoming area. Catalog completeness improves our assessment of a region's tectonic behavior and earthquake exposure. To look for recurring swarm or earthquake 
sequence behavior, I apply waveform correlation methods to scan two decades of continuous PDAR waveforms, comparing to several template events selected from the "Jackson Swarm" catalog, to identify repeating events from the source area of the swarm. 


\section{Regional Geology and Geologic History}

\subsection{Regional Deformation}

Central western Wyoming (Figure 2.1), a portion of the North American Cordillera comprised of sedimentary carbonate and clastic units, was part of the Cordilleran foreland basin during the Late Jurassic. Thin-skinned deformation and the resultant Sevier fold-and-thrust belt dominated the region causing flexural loading and subsidence until $\sim 81 \mathrm{Ma}$ (Fan and Carrapa 2014).

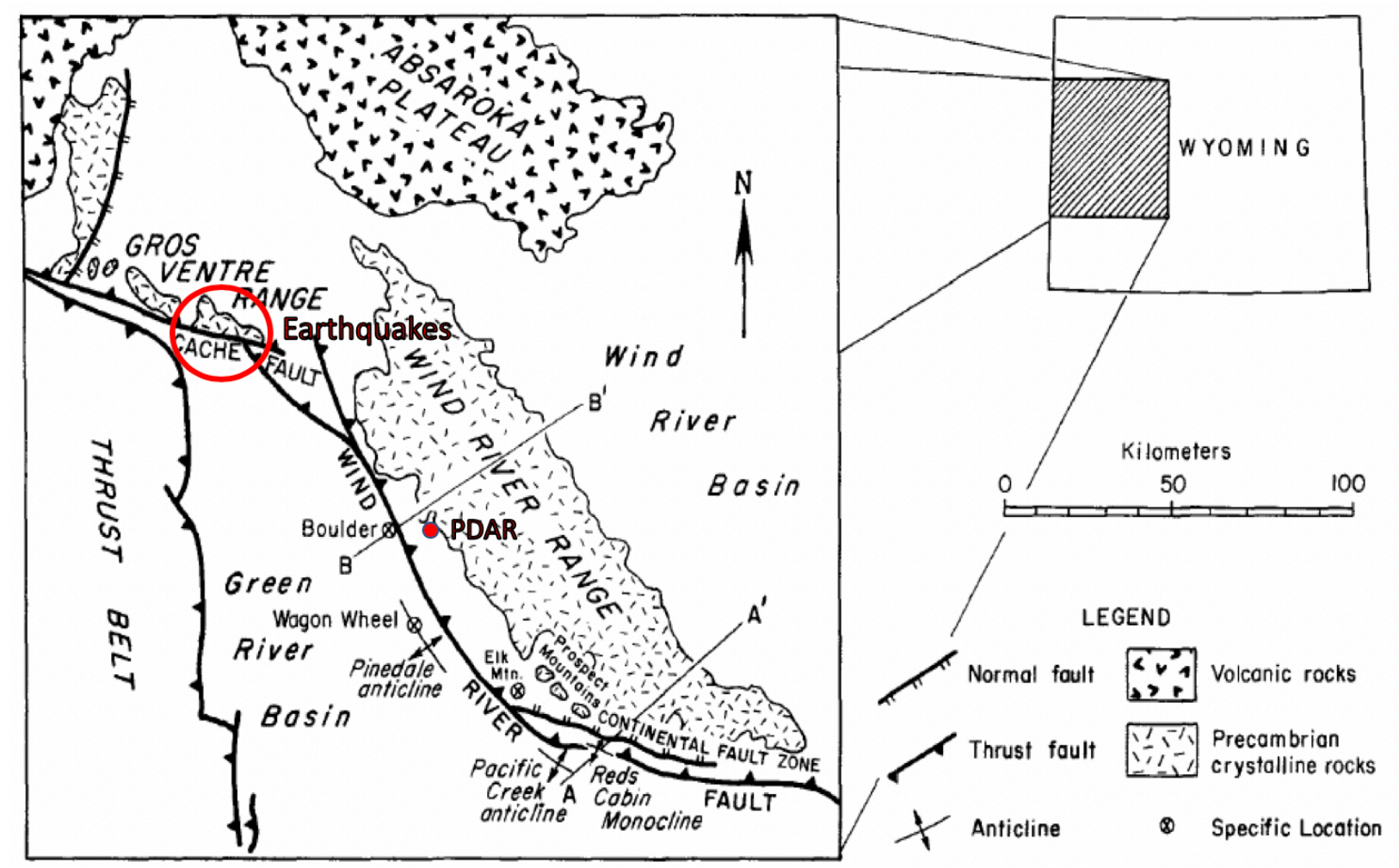

Figure 2.1: Regional Geology

The regional geology of central western Wyoming is highly deformed by orogenic events. The Pinedale Array (PDAR) location is shown to the west of the Wind River Range as a red dot. Northwest of the array, the region of the seismic sequence or swarm is outlined in red. Modified from Steidtmann and Middleton (1991). 
Laramide deformation and erosion began in the region in the Late Cretaceous with accelerated exhumation occurring from 65 to $50 \mathrm{Ma}$ (Keefer 1970; Stevens et al. 2016). The Laramide orogeny created thick-skin deformation in the region as the buoyant oceanic lithosphere of the Farallon plate led to a transition from high to low-angle subduction. There are multiple geodynamic models present in the literature to explain the resulting uplift. These models include: basal traction, movement of crustal material, addition of an end load at the trench, displacement of the lithosphere above the asthenosphere wedge causing stress, slab steepening, and slab rollback (Fan and Carrapa 2014).

Laramide deformation continued in the region until the mid-Eocene. Fan and Carrapa (2014) put the end of exhumation and subsidence at 45 Ma. Another period of uplift and erosion occurred during the Oligocene (Steidtmann and Middleton 1991; Stevens et al. 2016).

\subsection{Wind River Range}

The Wind River Range (WRR) is a large basement-cored, Laramide-style mountain range located in western Wyoming (Figure 2.1). The $145 \mathrm{~km}$ long range trends northwest-southeast and covers an area of roughly $6,000 \mathrm{~km}^{2}$ (Stevens et al. 2016). Emplacement of granitoids, granitoid gneisses, and migmatites of the WRR occurred during the Archean between 2.8 and $2.55 \mathrm{Ga}$, as well as high grade metamorphism (Figure 2.2) (Frost et al. 1998; Stevens et al. 2016). 


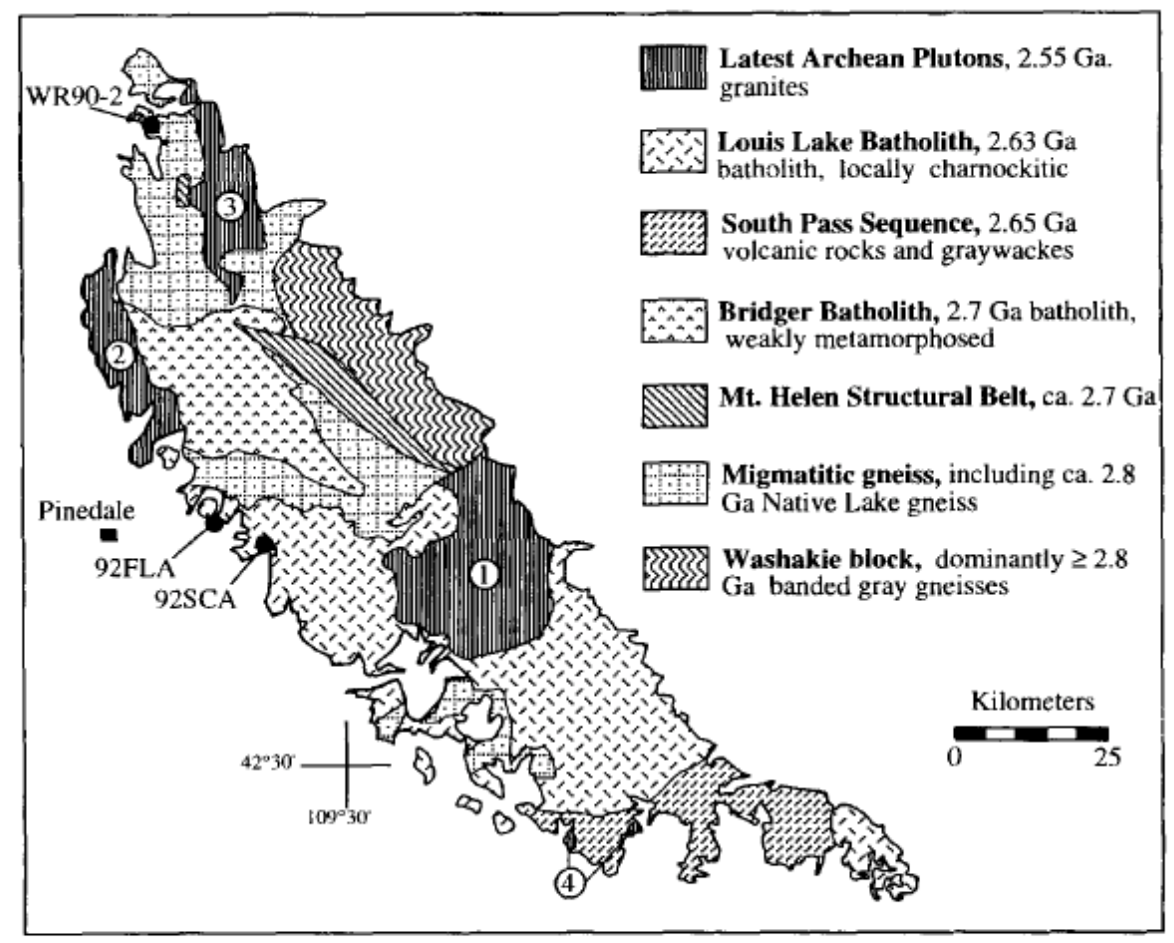

Figure 2.2: The Wind River Range

The intrusions of the WRR vary in age of emplacement (Frost et al. 1998).

During the Proterozoic the pluton was unroofed and exposed at the surface. The pluton was then buried under 4-6 km of sediment from the Paleozoic to the Mesozoic. Laramide deformation beginning in the Late Cretaceous formed the Wind River Fault (Figure 2.1) and created the WRR. Uplift and erosion continued until the Archean pluton was exposed again in the Eocene (Carroll et al. 2006; Stevens et al. 2016).

Oligocene uplift and erosion partially buried the WRR, although the amount of burial the range has experienced has not been conclusively determined. Steidtmann and Middleton (1991) postulate that the WRR was covered in its own eroded sediments by the Middle Eocene with the highest peaks forming topography and that uplift during the Oligocene created the current topography in the range. Stevens et al. (2016) conducted apatite fission track thermochronology 
and thermal-kinetic modeling on samples from the WRR and determined that the sedimentation created less than the $4 \mathrm{~km}$ thickness needed to cover a majority of the range; about $1 \mathrm{~km}$ of burial was detected instead.

\subsection{Green River Basin}

The Green River Basin (GRB) lies to the south of the northwest trending WRR. The GRB's northern boundary is the Wind River Thrust and its western boundary is the Sevier foldand-thrust belt (Figure 2.1). The basin formed as the result of flexure from the tectonic load of the WRR and the fold-and-thrust belt (Hagen et al. 1985; Steidtmann and Middleton 1991). Late Cretaceous to late Paleocene subsidence was slower than during the late Paleocene to middle early Eocene (Fan and Carrapa 2014).

The GRB is asymmetric, deepening to the east, with rock units that also thicken to the east (Hagen et al. 1985; Carroll et al. 2006; Fan and Carrapa 2014). Close to the WRR, the GRB has over $4 \mathrm{~km}$ of sedimentary rock deposited from the Late Cretaceous to the Eocene (Figure 2.3) (Stevens et al. 2016). The central GRB, proximal to the southern extent of the WRR, has 9 km of sedimentary rock from the Cambrian to the Paleogene (Smithson et al. 1978). 


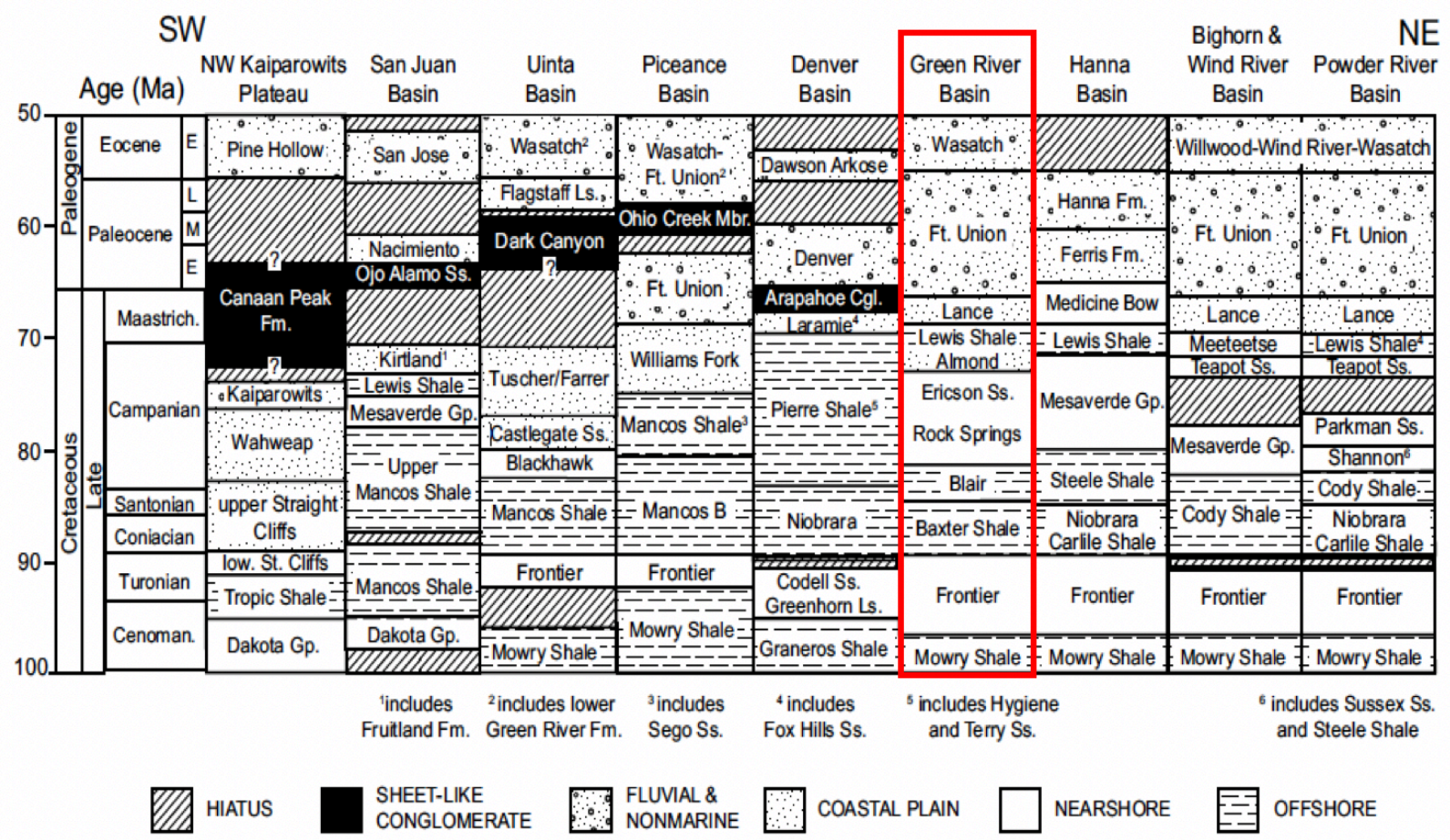

Figure 2.3: The Green River Basin

The GRB, outlined in red, contains sediment from the Cretaceous to the early Eocene. Modified from Heller and Liu (2016).

Deformation generated two anticlines near the basin's northeastern margin (Figure 2.1). The Pinedale anticline is asymmetrical with a steep western limb, $10 \mathrm{~km}$ wide, and is $56 \mathrm{~km}$ long running parallel to the Wind River fault. This structure has a relief of $610 \mathrm{~m}$. The age of the anticline is unknown. The Pacific Creek anticline is also asymmetrical with a steep southwestern limb and parallels the Wind River fault. The age of the formation of this anticline is estimated to be between 65 and $68 \mathrm{Ma}$ (Steidtmann and Middleton 1991). 


\subsection{Gros Ventre Range}

The Gros Ventre Range (GVR) is located northwest of the northern end of the WRR (Figure 2.1). The 24 to $32 \mathrm{~km}$ wide range trends northwest-southeast extending almost $65 \mathrm{~km}$ and is the location of the "Jackson Swarm". I will map the locations of the events relative to the local geologic structures and determine which faults may have been associated with the earthquakes.

The geologic and tectonic histories of the GVR and WRR are similar due to their proximity and location within the foreland basin. The core of the GVR is a metamorphosed pluton of gneiss and schist with granitic intrusions emplaced during the Precambrian. The pluton was exposed during the Paleozoic and sediments were deposited during the Paleozoic to Mesozoic. Laramide deformation also began during the Late Cretaceous and resulted in the uplift and erosion of the GVR (Nelson and Church 1943).

This deformation formed anticlines and a complex series of vertical, thrust, and high angle reverse faults that created a block like pattern in the range (Figure 2.4). A subset of these blocks is considered to be a trap-door structure. Four of these blocks trend northwest, with the age and deformation of these blocks decreasing to the east. West to east, these blocks are: Cache Creek, Skyline Trail, Shoal Creek, and Elbow Mountain (Nelson and Church 1943). 


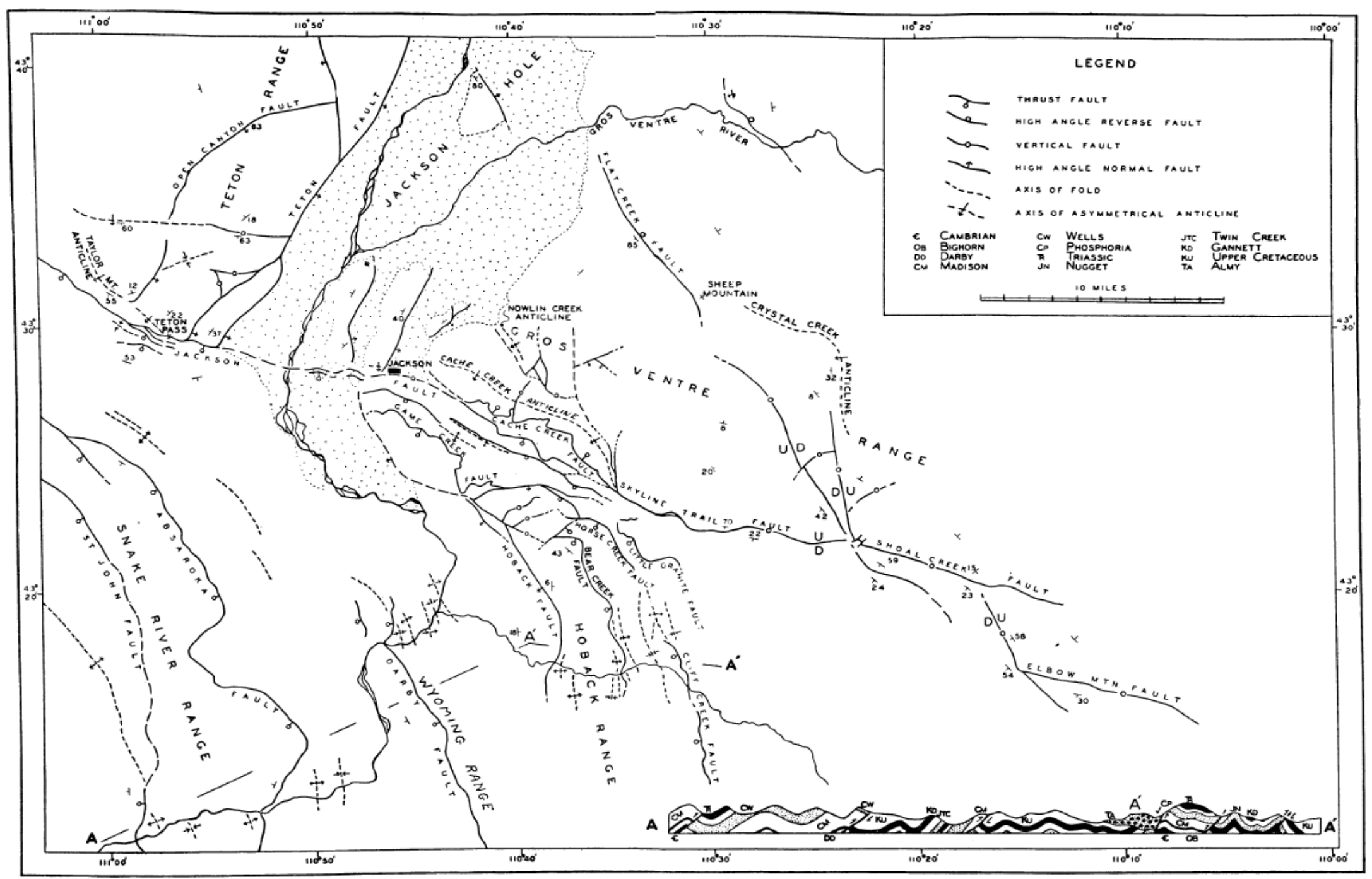

Figure 2.4: The Gros Ventre Range

The GVR is broken into blocks by a series of faults (Nelson and Church 1943). 
The Cache Creek thrust fault is associated with an anticline of the same name (Nelson and Church 1943; Dorr et al. 1977). The Cache Creek anticline is $\sim 14 \mathrm{~km}$ long and asymmetric with the south limb being steeper. Nowlin Creek anticline lies to the north and is similar in structure. Cache Creek thrust is the fractured southwestern limb of the Cache Creek anticline. The thrust fault abruptly ends as it runs into the Skyline Trail fault (Nelson and Church 1943). Dorr et al. (1977) and Steidtmann and Middleton (1991) map much of Nelson and Church's (1953) Skyline Trail fault as a continuation of the abutting Cache fault (Figure 2.1). Dorr et al.'s mapped Cache fault also extends further to the southeast passing to the south of the Elbow Mountain fault.

The Skyline Trail fault, as mapped by Nelson and Church, is almost $16 \mathrm{~km}$ long with either vertical or high angle reverse motion (Figure 2.5). The fault turns to the north at its western end and branches into the Sheep Creek fault. The Skyline Trail fault terminates to the east against the $\sim 14 \mathrm{~km}$ long Shoal Creek fault. The Shoal Creek fault has vertical or possibly high angle normal motion. The fault changes from a northwest strike to almost north for less than $5 \mathrm{~km}$ before terminating at its western end. The Crystal Creek anticline, found along the northern portion of the Shoal Creek fault block, is also asymmetric with a steeper southwest limb. The Pyramid Peak vertical fault branches from the southwest edge of the Shoal Creek fault, and the Elbow Mountain vertical fault is situated to the southeast. The Jackson Peak fault branches from the Elbow Mountain fault at the western block corner (Nelson and Church 1953; Dorr et al. 1977). The complexity of the faulting in the region likely suggests activation of multiple structures during the Jackson earthquake sequence. 


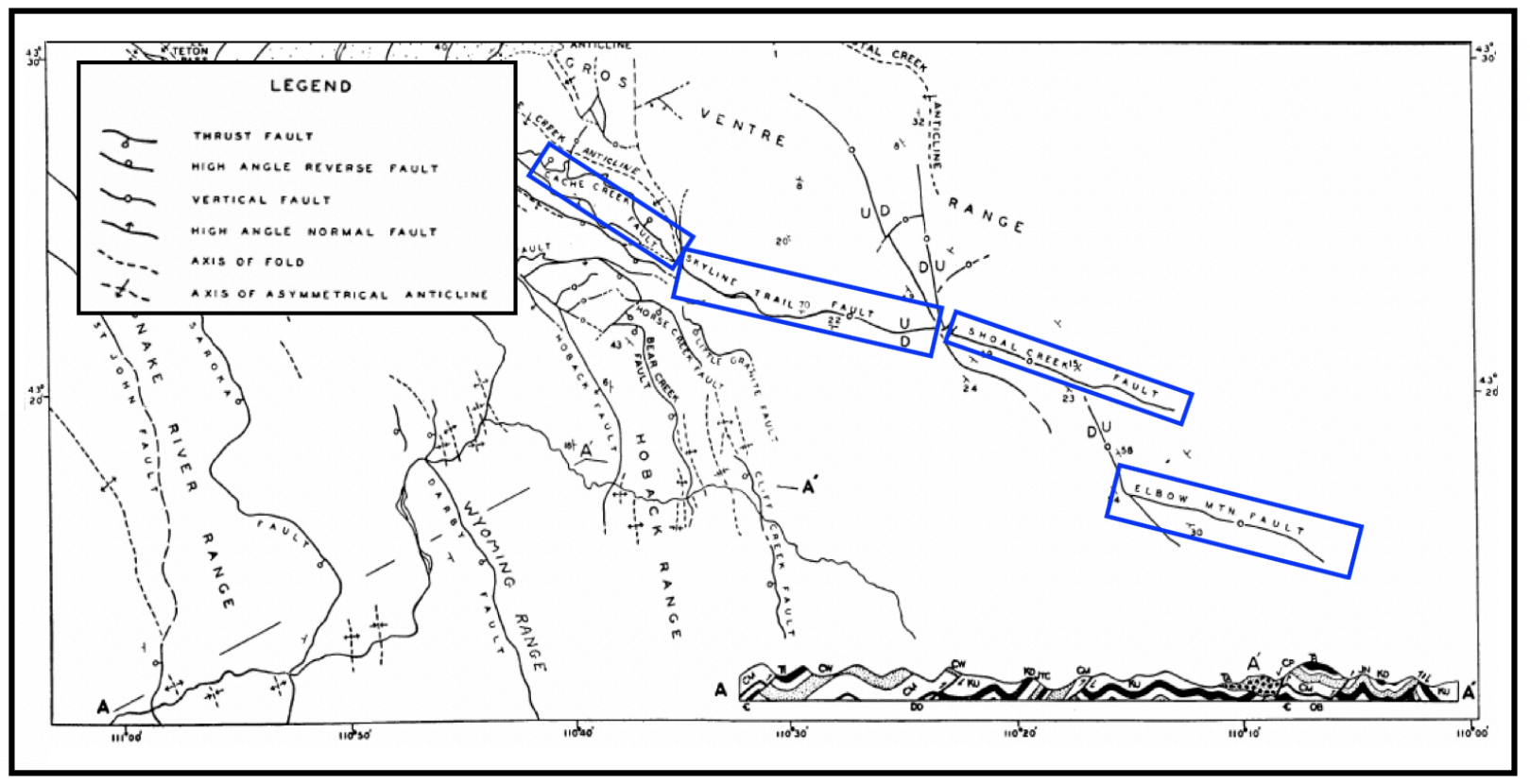

Figure 2.5: Southeastern Deformation

The southeastern deformation of the Gros Ventre region consists of vertical northwest-southeast trending faults. The major fault lines are outlined in blue. Modified from Nelson and Church (1943).

\subsection{Hoback Basin}

The Hoback Basin encompasses nearly 650 square kilometers and is located north of the GRB (Figure 2.1 and Figure 2.6). The two basins are separated by a small rim on the southern edge of the Hoback Basin creating two separate drainage systems. The Hoback Range, part of the Sevier fold and thrust belt, borders the basin to the west, while the eastern border of the basin is formed by the GVR. The triangle shape of the Hoback Basin is created by the convergence of the Hoback Range and the GVR at the northernmost point in the basin (Dorr 1952; Dorr et al. 1977). 
Similar to the GRB, clastic synorogenic deposition within the Hoback Basin started during the Late Cretaceous and ended during the late Pliocene. Sediments were also deposited from several stages of glacial activity during the Pleistocene (Dorr et al. 1977).

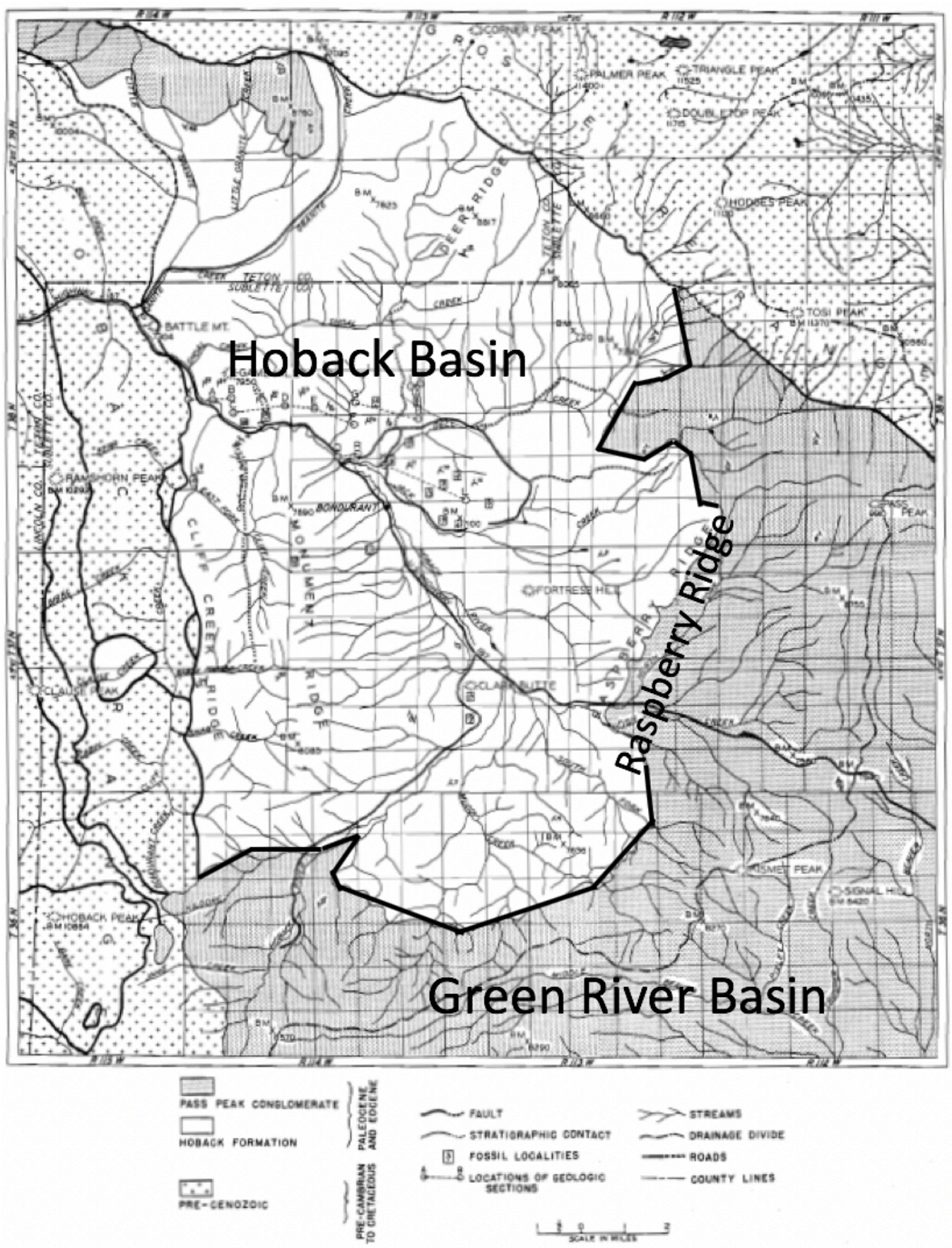

Figure 2.6: The Hoback Basin

The Hoback Basin is separated from the Green River Basin by the Raspberry Ridge (Dorr 1952). 


\section{Methodology}

\subsection{Data Collection}

The 58 known events, details listed in Appendix, from the MBMG network catalog were cut to the previous minute from the continuous waveform data recorded by the surface components (Figure 3.3.1) of the PDAR array and converted to Seismic Analysis Code (SAC) files. The continuous data is housed on the Los Alamos National Laboratory (LANL) Groundbased Nuclear Detonation Detection (GNDD) seismic database. The array has a dense circular geometry with the two borehole stations towards the center.

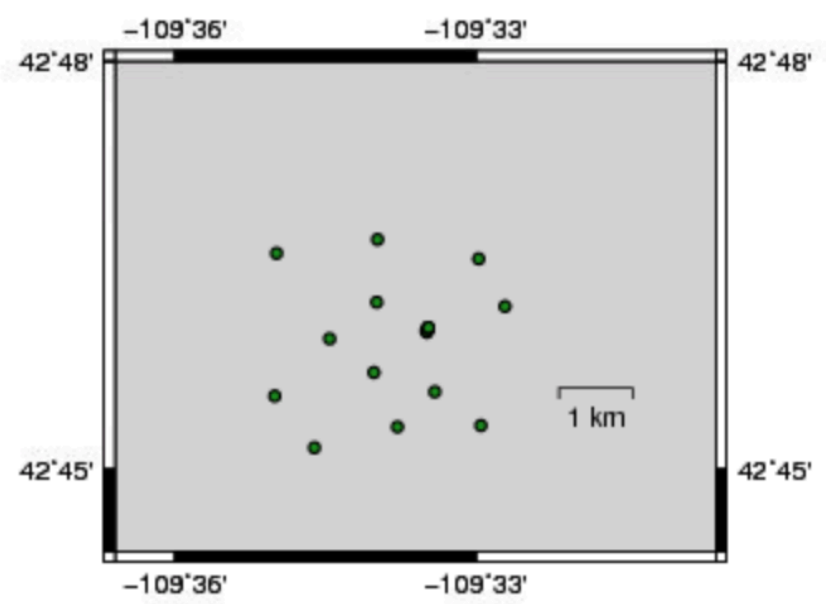

Figure 3.1.1: PDAR Components

The location of the surface components $(1-13)$ are shown relative to one another and the borehole stations $(31 / 32)$.

\subsection{Earthquake Location Verification Utilizing a Network}

The locations of the hypocenters of many earthquakes are determined from the difference in the arrival times of certain phases of the seismic waves and the velocity at which these waves travel in the subsurface. These locations are highly dependent on the accuracy of the recorded arrival times and the assumed regional velocity model. This event location technique is often 
erroneous, leading to the creation of more accurate location techniques for seismic networks such as Hypoinverse.

Hypoinverse is an earthquake location technique created by Klein (2014) that utilizes FORTRAN code, which will be used in this study to validate the cataloged network locations provided by the MBMG. Input files for the program include a list of station locations, a phase file with $\mathrm{P}$ wave and $\mathrm{S}$ wave arrival times, and a flat earth velocity model. These can be entered at command line in the program or compiled into a command file or hyp file.

Other parameters can also be added to help stabilize the location process. These include options to add station delays and attenuation factors, calibration information, magnitude corrections, and to fix earthquake depths.

The original swarm event locations were determined by the Montana Bureau of Mines and Geology (MBMG) at Montana Tech using the MBMG's Montana Regional Seismic Network (MB) and stations from the following networks (Figure 3.2.1): Canadian National Seismograph Network (CN), Global Seismograph Network (IU), INL Seismic Monitoring Program (IE), BYU-Idaho Network (RC), Intermountain West Seismic Network (IW), Yellowstone Wyoming Seismic Network (WY), United States National Seismic Network (US), Pacific Northwest Seismic Network (UW), and USArray Transportable Array (TA). 


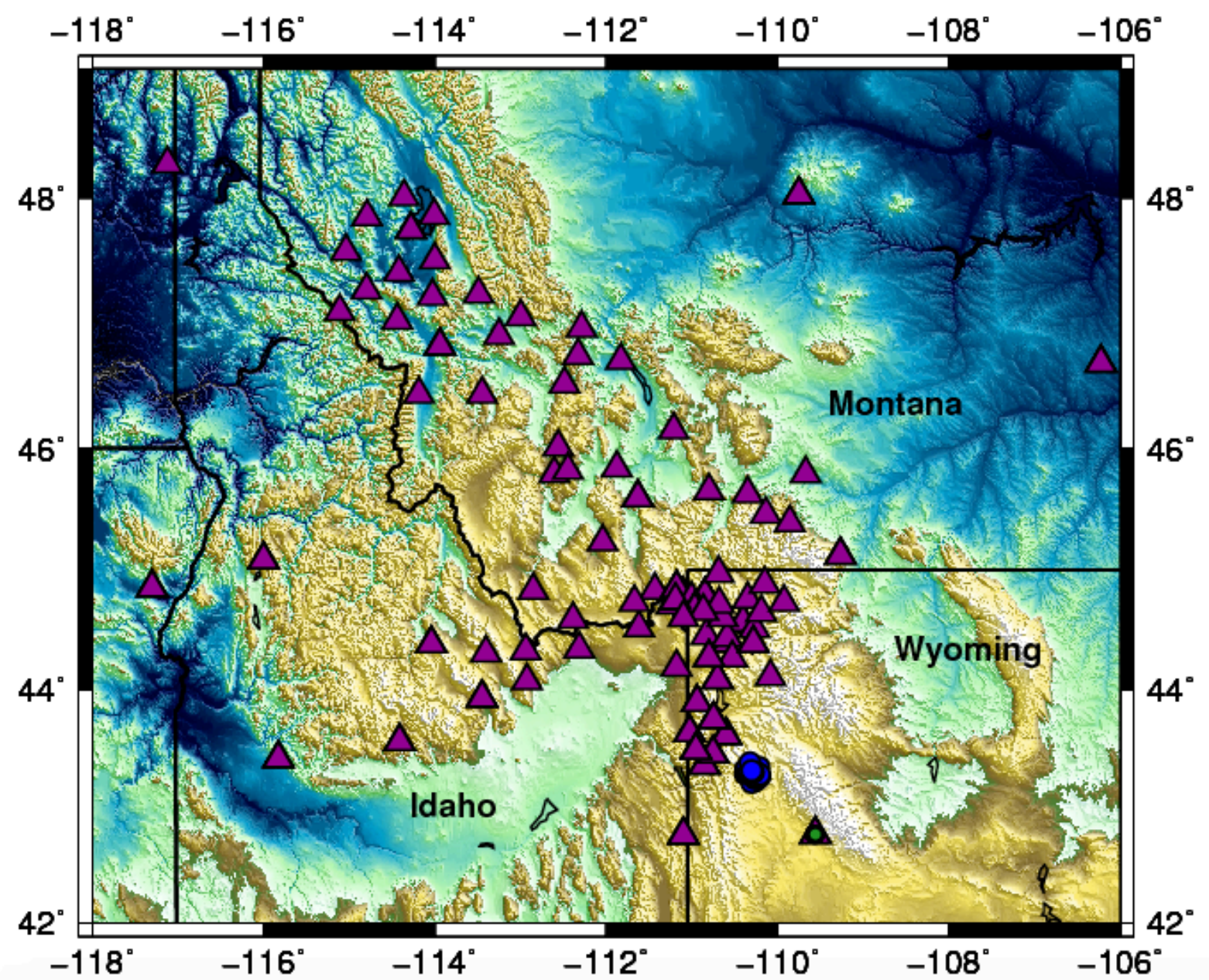

Figure 3.2.1: Network Station Locations

Stations from networks used by the MBMG, shown in magenta triangles, cover northwestern Wyoming, central Idaho, and western Montana. The PDAR array is shown as a green circle located to the southeast of the cluster of blue circles that denote the swarm event locations. One network station is colocated with PDAR station PD06 therefore a network station triangle lies below the PDAR symbol.

The parameters the MBMG employed to locate the events were provided, with the help of the University of Utah, and utilized in generating the Hypoinverse command file (Appendix). These include the residual weighting, standard timing error, RMS and $\mathrm{S}$ weighting factor, $\mathrm{P}$ to $\mathrm{S}$ 
ratio, minimum number of stations, trial depth, initial and main distance weighting, and damping and convergence controls.

The $\mathrm{P}$ wave and $\mathrm{S}$ wave velocity model (Table 3.2.1) applied in the location of the swarm events was derived from Brumbaugh (2001). Brumbaugh's velocity model was adapted from the Pechmann et al. (1997) P wave velocity model based on $\mathrm{P}$ wave travel times calculated from three mine blasts and 11 aftershocks in conjunction with previously published crustal and mantle velocities (Braile et al. 1974; Sparlin et al. 1982) to develop a working velocity model for the Draney Peak region. Brumbaugh revised this model using the 1994 Draney Peak, Idaho earthquake and subsequent aftershocks to determine a $\mathrm{P}$ to $\mathrm{S}$ wave velocity ratio of $1.78+/-0.1$ from the station pair method (Brumbaugh 2001; J. Pechmann, personal communication, 2018).

Table 3.2.1: Draney Peak Velocity Model

The velocity model used in the Hypoinverse code for the $\mathrm{P}$ and $\mathrm{S}$ wave velocities has a ratio of 1.78 (Brumbaugh 2001).

\begin{tabular}{|c|c|c|}
\hline Depth $(\mathrm{km})$ & P Velocity $(\mathrm{km} / \mathrm{s})$ & S Velocity $(\mathrm{km} / \mathrm{s})$ \\
\hline 0.0 & 4.7 & 2.64 \\
\hline 3.2 & 5.1 & 2.87 \\
\hline 4.8 & 5.6 & 3.15 \\
\hline 6.4 & 6.1 & 3.43 \\
\hline 8.2 & 6.2 & 3.48 \\
\hline 23.2 & 6.8 & 3.82 \\
\hline 43.2 & 7.9 & 4.44 \\
\hline
\end{tabular}


Once I set up the command file to use the same parameters as employed by the MBMG to locate the earthquake sequence, I ran the program to determine if I could validate the catalog locations.

\subsection{Earthquake Location Utilizing Seismic Array Processing}

The methodology for locating earthquakes using an array differs from the previous process for locating events using a seismic network due to the lack of spatial distribution and array geometry. The following sections outline the process used to determine the event locations using the array data.

\subsubsection{Picking $\mathrm{P}$ and S Wave Arrivals}

Of the 58 known events, 14 of the traces had little noise and $\mathrm{P}$ and $\mathrm{S}$ wave arrivals were picked without the aid of filtering. The remaining events were filtered using a bandpass filter in order to confirm the picked arrivals were accurate. A majority of the events required a filter from 1 to $9 \mathrm{~Hz}$ to ascertain the accuracy of the arrivals. The events with the poorest signal to noise ratio were filtered using a band pass of 2 to $8 \mathrm{~Hz}$.

\subsubsection{Beam Forming}

Beam forming, as summarized from Rost and Thomas (2002), is used to separate noise or incoherent parts of seismic array data from the coherent signals. This is accomplished by determining the differences in arrival times of wave fronts at different stations in the array. The differences are caused by differences in the back azimuth $(\theta)$ and specific slowness $(u)$ of the seismic waves, where the equation for $u$, the inverse of velocity, equals: 


$$
u=\frac{1}{v_{a p p}}=\frac{\sin i}{v_{0}}
$$

where $v_{a p p}$ is the apparent velocity of the wave front, $v_{0}$ is the medium velocity beneath the array, and $i$ is the angle of incidence.

The back azimuth $(\theta)$ is the angle between north and the direction of the epicenter of the incoming wave front to the station (Figure 3.3.1). The back azimuth and slowness are used to determine the slowness vector $\mathbf{u}$ in a spherical coordinate system:

$$
\begin{gathered}
\mathbf{u}=\left(u_{x}, u_{y}, u_{z}\right) \\
=\left(\frac{\sin \theta}{v_{a p p}}, \frac{\cos \theta}{v_{a p p}}, \frac{1}{v_{a p p} \tan i}\right) \\
=u_{\text {hor }}\left(\sin \theta, \cos \theta, \frac{1}{\tan i}\right) \\
=\frac{1}{v_{0}}(\sin i \sin \theta, \sin i \cos \theta, \cos i)
\end{gathered}
$$

where $v_{a p p}$ is the apparent velocity of the wave front, $v_{0}$ is the velocity of the material beneath the array, $i$ is the angle of incidence, and $u_{h o r}$ is the horizontal slowness. 


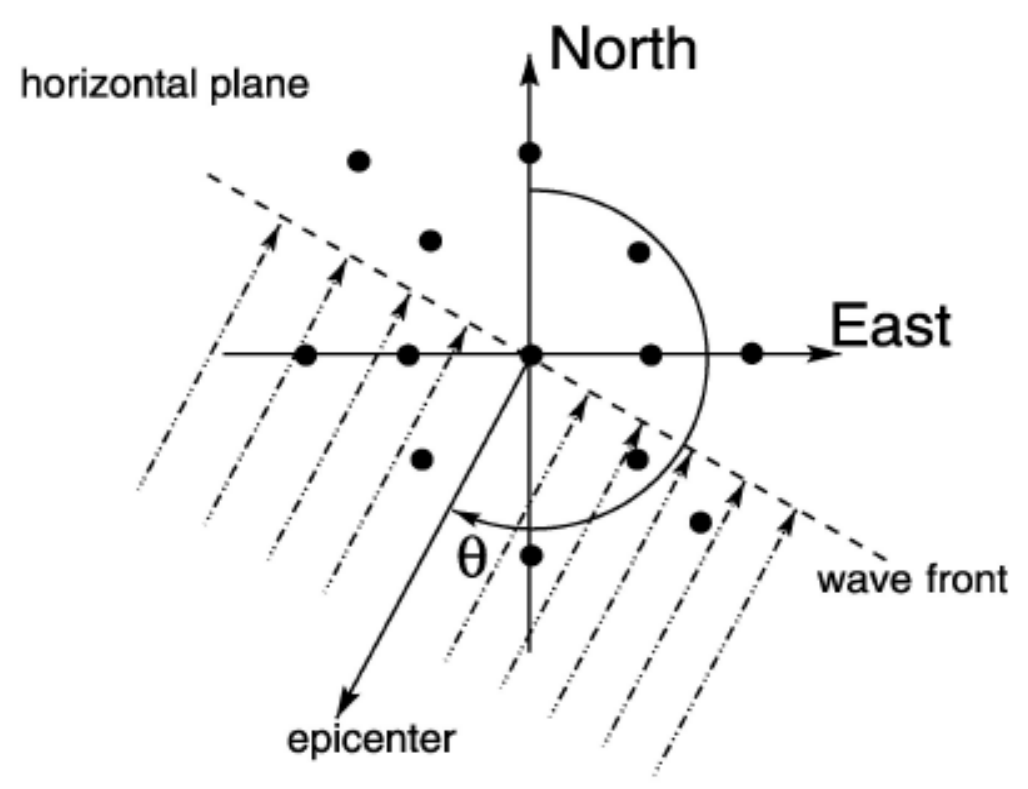

Figure 3.3.1: Back Azimuth

The back azimuth $(\theta)$ is the angle between north and the direction of the epicenter of the incoming wave front to the station (Rost and Thomas 2002).

In order to determine the difference between coherent and incoherent signals, it is necessary to calculate the time series each station records starting with the central station or what the array center would record if a station was present:

$$
x_{\text {center }}(t)=f(t)+n_{i}(t)
$$

where $f(t)$ is the signal and $n_{i}(t)$ is the noise recorded at $x_{c e n t e r}$, the center station.

Because the travel time of the seismic wave to each station is different due to its location and the horizontal wave front slowness $\left(u_{\text {hor }}\right)$, another equation for the array's other stations must be derived:

$$
x_{i}(t)=f\left(t-r_{i} * u_{h o r}\right)+n_{i}(t)
$$


where $x_{i}$ is an array station and $r_{i}$ is the station $(i)$ location vector.

The time shift between traces recorded at stations in the array can then be removed using the following equation:

$$
\tilde{x}_{i}(t)=x_{i}\left(t+r_{i} * u_{\text {hor }}\right)=f(t)+n_{i}\left(t+r_{i} * u_{\text {hor }}\right)
$$

The "delay and sum" method can them be applied to the traces of an array having $M$ number of components using the equation:

$$
b(t)=\frac{1}{M} \sum_{i=1}^{M} \tilde{x}_{i}(t)=f(t)+\frac{1}{M} \sum_{i=1}^{M} n_{i}\left(t+r_{i} * u_{h o r}\right) .
$$

The goal of this method is repressing noise and intensifying phases with similar slownesses, and the more stations present in the array the more the noise can be suppressed. The improvement in the signal-to-noise ratio between the station $(s)$ and the array $(S)$, as determined by Harjes and Henger (1973), can be approximated by:

$$
S \approx \sqrt{M S}
$$

The improvement in the signal to noise ratio on the beam of the PDAR stations for an event assisted in the picking of the $\mathrm{P}$ and $\mathrm{S}$ wave arrival times when distinguishing between the noise and the arriving seismic wave was difficult. These arrival times were later used to calculate the distance between the source and receiver in the location calculations. 


\subsubsection{F-K Analysis}

F-K analysis or frequency-wave number analysis, as outlined by Rost and Thomas (2002), determines the slowness vector and measures the direction of advance and power divided between different slownesses (Harjes and Henger 1973). As with the beam forming analysis, F-K analysis uses the difference in arrival times at different stations to study seismic phases.

The best possible combinations of back azimuth $(\theta)$ and slowness $(u)$ can be determined by using a grid search, which can be used in the equation to determine the signal recorded at a station:

$$
\begin{gathered}
x_{n}(t)=s\left(t-\mathbf{u}_{0} r_{n}\right), \text { where } \\
\mathbf{u}_{0}=\frac{1}{v_{0}}(\cos \theta, \sin \theta), \text { or }
\end{gathered}
$$

where $\mathbf{u}_{0}$ equals the slowness vector and $\mathbf{s}(t)$ represents an arriving signal.

The signals for the stations are then time shifted and summed together to reach the maximum amplitude; the array output can be calculated as:

$$
y(t)=\frac{1}{N} \sum_{n=1}^{N} x_{n}\left(t+\mathbf{u}_{0} r_{n}\right),
$$

where $N$ is equal to the number of stations in the array. If a signal has a different slowness vector (u) the beam trace can still be calculated through the equation:

$$
y(t)=\frac{1}{N} \sum_{n=1}^{N} s\left\{t+\left[\left(\mathbf{u}_{0}-\mathbf{u}\right) * r_{n}\right]\right\} .
$$

Calculating the total energy $(E)$ that is recorded by the array uses Parseval's theorem expressed as: 


$$
\begin{gathered}
E\left(k-k_{0}\right)=\int_{-\infty}^{\infty} y^{2}(t) d t \\
=\frac{1}{2 \pi} \int_{-\infty}^{\infty}|S(\omega)|^{2}\left|\frac{1}{N} \sum_{n=1}^{N} e^{2 \pi i *\left(\mathbf{k}-\mathbf{k}_{0}\right) * r_{n}}\right|^{2} d \omega
\end{gathered}
$$

where, $S(\omega)$ equals the Fourier transform of $\mathrm{s}(\mathrm{t})$, and $\mathbf{k}$ equals the wave number vector.

$$
\mathbf{k}=\left(k_{x}, k_{y}\right)=\omega * \mathbf{u}=\frac{\omega}{v_{0}}(\cos \theta, \sin \theta)
$$

and $\mathbf{k}_{\mathbf{0}}$ equals the wave number vector for $\mathbf{u}_{0}$.

This can be rewritten as:

$$
E\left(\mathbf{k}-\mathbf{k}_{\mathbf{0}}\right)=\frac{1}{2 \pi} \int_{-\infty}^{\infty}|S(\omega)|^{2}\left|A\left(\mathbf{k}-\mathbf{k}_{\mathbf{0}}\right)\right|^{2} d \omega
$$

where the array response function equals,

$$
\left|A\left(\mathbf{k}-\mathbf{k}_{\mathbf{0}}\right)\right|^{2}=\left|\frac{1}{N} \sum_{n=1}^{N} e^{2 \pi i *\left(\mathbf{k}-\mathbf{k}_{\mathbf{0}}\right) * r_{n}}\right|^{2}
$$

The power spectral density $\left(|S(\omega)|^{2}\right)$ and the array response function determine the array's total recorded energy. The array response function, in turn, is defined by the arrays spacing, configuration, and aperture. This processing technique results in the power spectral density as a function of back azimuth and slowness, both of these parameters can be determined using the wave number vector $\mathbf{k}=\left(k_{x}, k_{y}\right)$. 
The equations for the apparent horizontal slowness $\left(u_{s}\right)$ and back azimuth $(\theta)$ are as follows:

$$
\begin{gathered}
|\mathbf{k}|=\left(k_{x}^{2}+k_{y}^{2}\right)^{\frac{1}{2}}=\frac{2 \pi}{u_{s}}=\frac{\omega}{v_{s}^{\prime}} \\
u_{s}=\frac{2 \pi}{|\mathbf{k}|}, \text { and } \\
\theta=\tan ^{-1}\left(\frac{k_{x}}{k_{y}}\right) .
\end{gathered}
$$

The F-K diagram (Figure 3.3.2), a polar coordinate system projection, displays the power spectral density, the back azimuth on an azimuthal axis, and slowness on a radial axis.

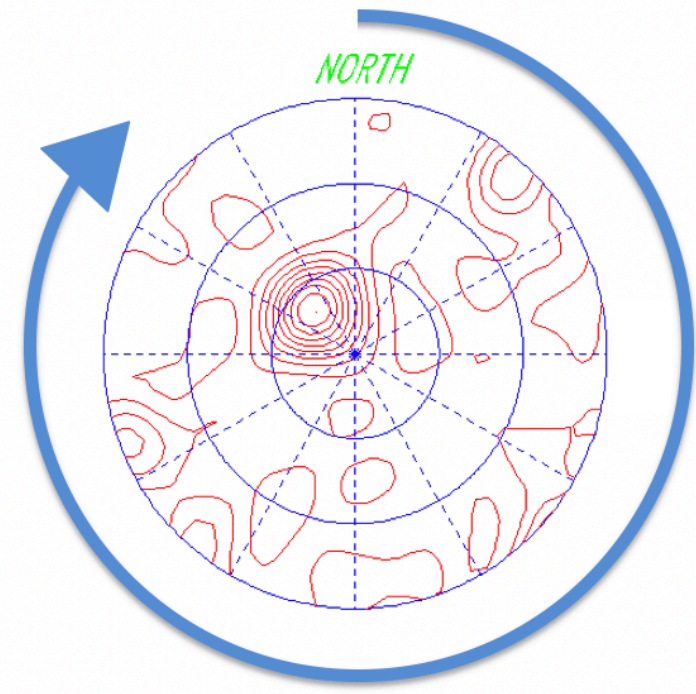

Figure 3.3.2: The F-K Diagram

The F-K diagram for an event during the Jackson seismic sequence (08/28/2016 at 10:33 AM) has a back azimuth of 317.5 degrees, indicated with a blue arrow. 
The F-K diagrams for this study were generated using Seismic Analysis Code (SAC). Once the seismograms of an event for all the stations in the array are read into the program, they are cut into three eight-second-long sections: noise, $\mathrm{P}$ wave, and $\mathrm{S}$ wave coda.

After a section is cut from the seismograms and it is then demeaned and detrended. Once this process is complete, I conducted a Fast-Fourier Transform (FFT) keeping only the amplitude information and generated plots of the amplitudes of the recorded frequencies. Examples of FFT plots for high, average, and low signal to noise ratios (SNR) are shown in Figure 3.3.3.

The SNRs were calculated using Octave, the open source alternative to Matlab. I converted the cut section of noise and signal to ASCII files, which outputs values for the amplitude of the seismic trace over time and loaded these files into Octave. In Octave, I performed root mean square (rms) calculations on the amplitude values, and determined the ratio for the $\mathrm{P}$ and $\mathrm{S}$ wave $\mathrm{SNR}$ using the signal rms divided by the noise rms. 

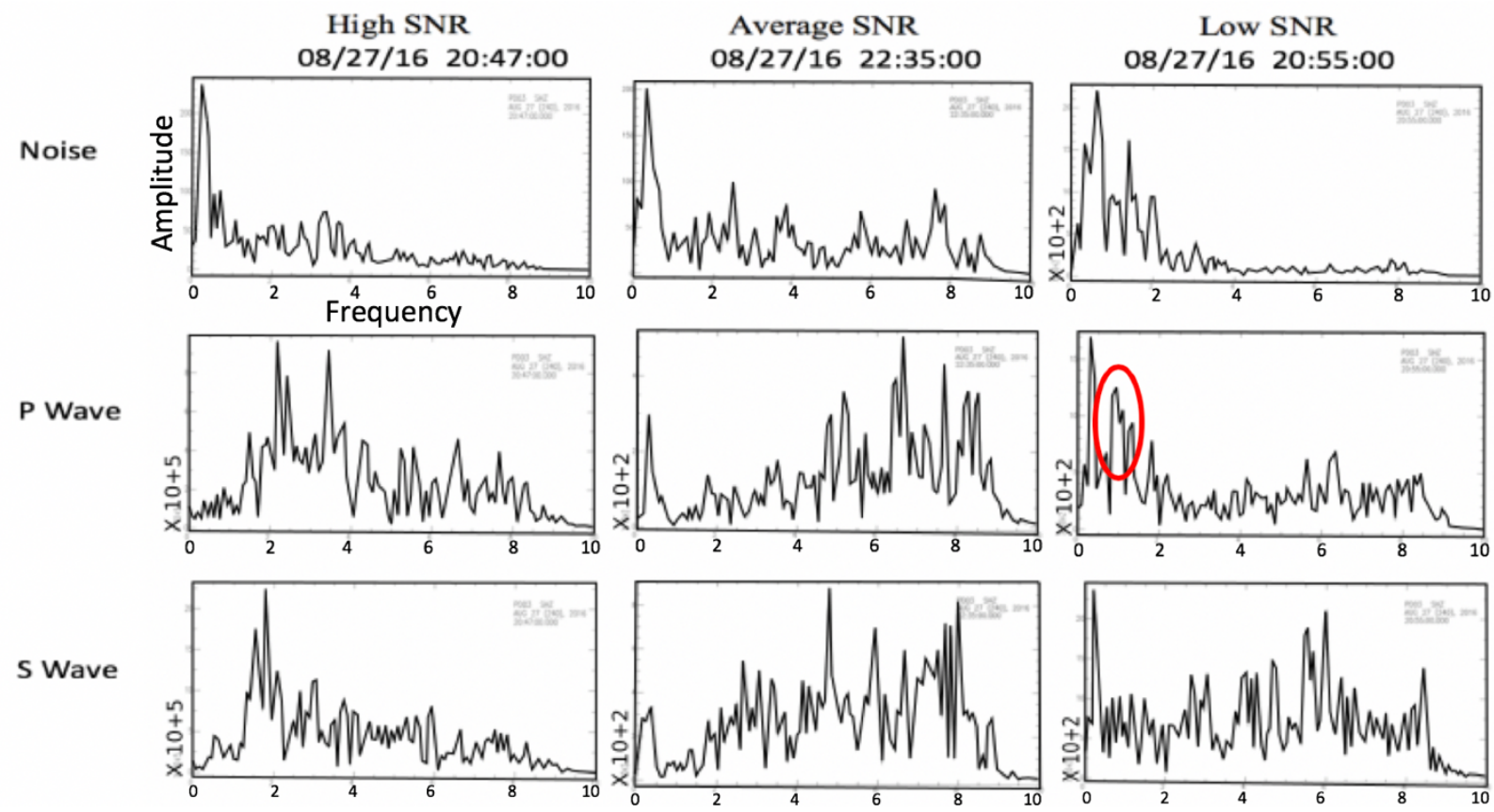

Figure 3.3.3: FFT Plots

The signal to noise ratios for events with high, average, and low ratios. A bandpass filter was chosen by determining a range of frequencies for which there was little noise compared to the earthquake signal. A peak in the earthquake signal for the $\mathrm{P}$ wave at frequencies between $1-2$ $\mathrm{Hz}$ is outlined in red and was determined to be the best possible bandpass for the data.

The events shown in Figure 3.3.3 occurred on August 27 th 2016 at 20:47, 20:55, and 22:33 with $\mathrm{P}$ wave SNRs of 6323.70 (high), 0.89 (low), and 3.35 (average) respectively. A table of the P wave and $\mathrm{S}$ wave SNRs can be found in the appendix.

A broadband frequency-waveform (BBFK) analysis, which produces F-K plots, was run in $\mathrm{SAC}$ on the representative sections of noise, $\mathrm{P}$ wave, and $\mathrm{S}$ wave signal that were cut from the event waveforms. The F-K peaks, back azimuth, and wave number were determined for each of the cut sections when generating the F-K plots. 
The BBFK analysis was run on each cut section without filtering. Next, the $\mathrm{P}$ wave and $\mathrm{S}$ wave sections were also run with filters of $2-8 \mathrm{~Hz}$ and $2-6 \mathrm{~Hz}$ in an effort to resolve a clear non-noise F-K peak. This filtering proved inadequate to remove the effect of the noise on the signal.

Adjacent bandpass windows of $1 \mathrm{~Hz}$ and $2 \mathrm{~Hz}$ from $0.01 \mathrm{~Hz}$ to $8 \mathrm{~Hz}$ were then used to isolate the signal and produce the best F-K peaks at $1-2 \mathrm{~Hz}$. The FFT plots were utilized to confirm the best bandpass filter was chosen to calculate the back azimuth and wavenumber. In Figure 3.3.3, a red circle highlights the peak in amplitude between 1 and $2 \mathrm{~Hz}$ in the low signal to noise ratio event's P wave FFT plots. A table of the results for the BBFK analysis can be found in the Appendix.

\subsubsection{Distance Determinations}

I calculated the distance $(d)$ from the source to the array using the following equation:

$$
d=\frac{\left(t_{s}-t_{p}\right)}{\left(\frac{1}{v_{s}}-\frac{1}{v_{p}}\right)}
$$

where $t_{s}$ and $t_{p}$ are the arrival times for the $\mathrm{S}$ and $\mathrm{P}$ waves, and $v_{s}$ and $v_{p}$ are the velocities for the $\mathrm{S}$ and $\mathrm{P}$ waves. In order to determine the most accurate array method to calculate the location of the seismic sequence, I compare the location results from using different velocities derived from the average velocity of the seismic waves as they travel through the subsurface and velocities computed during the BBFK analysis.

The average velocity method of calculating the distance from the array to the source utilizes trigonometric principles. To determine the average velocity, I needed to find the time that the seismic waves take to travel the distance between each velocity layer as shown in Table 3.2.1. The time in each layer depends on the velocity and the distance the wave must travel. I 
worked from the layer with the fastest velocity to determine the critical angle at the Moho depth for the region and then moved toward the surface to determine the subsequent refracted angles. The equation to calculate the critical angle $\left(\theta_{c}\right)$ is:

$$
\sin \theta_{c}=\frac{v_{1}}{v_{2}} .
$$

This critical angle is the same angle as the refracted seismic wave that traveled through the layer with $v_{1}$, and using Snell's Law it is possible to calculate the incident wave from the previous velocity layer. This process is repeated until reaching the surface. The following equation is Snell's Law:

$$
\frac{\sin \theta_{1}}{v_{1}}=\frac{\sin \theta_{2}}{v_{2}},
$$

where $\theta_{1}$ is the incident wave, $\theta_{2}$ is the angle of refraction, and $v_{1}$ and $v_{2}$ are the velocities of the corresponding layers.

When the angle of refraction of a seismic wave and the thickness of the velocity layer the wave entered is known, the distance the wave travels in the layer, at the refracted angle, can then be calculate using the trigonometric function cosine (Figure 3.3.4). The cosine of an angle $\theta$ is defined as:

$$
\cos \theta=\frac{\text { adjacent }}{\text { hypotenuse }}=\frac{Y}{X},
$$

where the adjacent length of a triangle is divided by the length of the hypotenuse. The hypotenuse in this model is the distance the seismic wave travels in a given layer. 


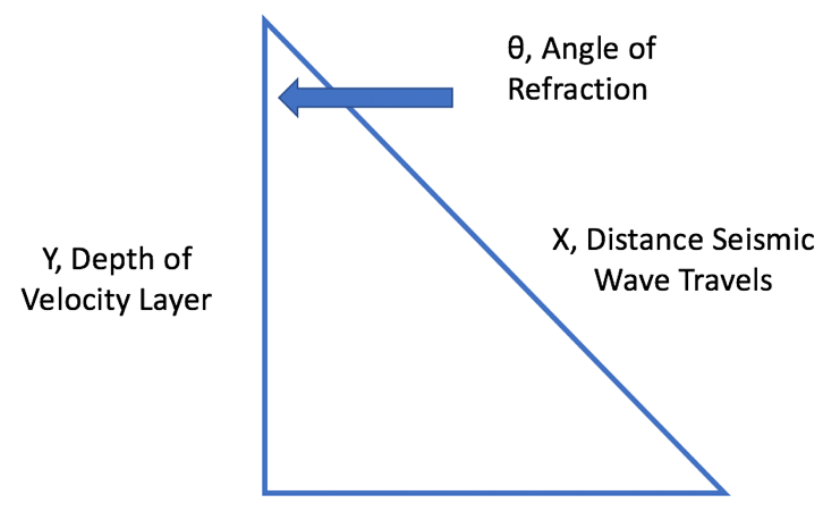

Figure 3.3.4: Cosine

The cosine of an angle is the length of the adjacent side of the triangle divided by the hypotenuse. This image is a simplified visualization of a seismic wave entering a subsurface layer with a new velocity where it is refracted to travel at angle $\theta$ for distance $X$ until entering a new velocity layer.

Once the distance the wave travels in each velocity layer is known, the time the wave takes to travel through each layer is calculated by dividing the distance by the velocity of the layer. The seismic wave travels through each velocity layer twice excluding the velocity layers within an average of $6 \mathrm{~km}$ of the surface. The one-way and two-way travel times are then subtracted from the reported travel time of each event. The remaining time left over is the time that the seismic wave travels along the boundary of the final velocity layer, at the higher velocity, before starting the return to the surface. The time that the seismic wave spends at each velocity is now known and an average velocity can be calculated using the following equation:

$$
v_{\text {avg }}=\frac{\left(t_{1}\right)\left(v_{1}\right)+\left(t_{2}\right)\left(v_{2}\right) \ldots+\left(t_{n}\right)\left(v_{n}\right)}{t_{\text {total }}}
$$


The second method of determining velocities is performed in SAC when running the BBFK analysis. The F-K plots that are produced for each seismic event lists in the terminal window wavenumbers. The wavenumbers are converted to slownesses via the following equation:

$$
\text { slowness }=2 \times \frac{\pi}{\text { wavenumber }} .
$$

The slownesses are reciprocated to calculate velocities that have units of degrees per second and are then converted to kilometers per second.

\subsubsection{Latitude and Longitude Calculations}

I have calculated the distance between the seismic sequence and the array and determined the bearing from the array to the source using BBFK analysis. The latitude and longitude of the seismic events can be calculated from this data. The equation for determining latitude and longitude can be written as:

$$
\begin{aligned}
& l_{a t}=\left(\operatorname{asin}\left(\sin \left(\text { lat }_{1}\right) \times \cos \left(\frac{d}{R}\right)+\cos \left(\text { lat }_{1}\right) \times \sin \left(\frac{d}{R}\right) \times \cos (\text { bearing })\right),\right. \\
& \operatorname{lon}_{2}=\operatorname{lon}_{1}+\operatorname{atan} 2\left(\cos \left(\frac{d}{R}\right)-\sin \left(\text { lat }_{1}\right) \times \sin \left(\text { lat }_{2}\right),\right. \\
& \left.\sin (\text { bearing }) \times \sin \left(\frac{d}{R}\right) \times \cos \left(\text { lat }_{1}\right)\right)
\end{aligned}
$$

where $l a t_{1}$ and $l o n_{1}$ are the location of the array, $d$ is the distance between the source and the array, and $R$ is the radius of the earth at the study area. 


\subsection{Cross-Correlation Swarm Reoccurrence Scan}

Waveform cross-correlation is a powerful tool used in seismology for a variety of applications involving the comparison of digital waveforms. Since seismological data acquisition moved widely into the digital realm, such signal processing methods have enjoyed widespread use for documenting the differences, and similarities, among seismograms. In this study, the highly concentrated activity in both space and time suggested that the seismic sequence could represent a seismic swarm, which is often a recurring phenomenon over decadal time scales (e.g., Stankova et al. 2008).

In the event of repeating seismic sources, it has been shown that events having similar mechanisms and arising in the same source location will exhibit similar waveforms at any given receiver. This is because, within a limited magnitude range, the source impulse produces the same fundamental signal and the Earth structure through which it passes imposes the same effects upon the signal, including scattering, attenuation and site effects particular to a given station.

Although the Jackson sequence events in this study are not accompanied by waveforms for the catalog locations among the regional networks, the nearby PDAR array has been operating for decades and affords us the opportunity to search through continuous digital seismic data for repeating events, leveraging the power of waveform cross-correlation.

The cross-correlation algorithm used in this study was modified from a retroactive, crosscorrelation-based phase repicking algorithm of Rowe (2000), Aster and Rowe (2000) and Rowe et al. (2002). The correlator itself, written in the C programming language, compares a waveform template to continuous waveform data at user-determined times, calculating the cross-correlation coefficient for each comparison and reporting the correlation value, maximum correlation lag time for that value, and the position in the time series where the comparison was made. The code 
is driven by a Python script which leverages the Pisces routines (MacCarthy and Rowe 2014) for accessing waveforms directly from the Oracle database where they reside.

Visual inspection of the PDAR waveforms for the extracted Jackson sequence events yielded intriguing additional events not included in the catalog, inspiring the question of whether additional, undetected, events could be extracted for the Jackson sequence using the PDAR continuous data. This motivated the cross-correlation scanning.

The methodology adopted is as follows:

1) Identify an event waveform whose repeatability we wish to test.

2) Create a template (in this case, using SAC) that will be compared against the continuous archive of waveforms for the selected station.

3) Execute the Python script that extracts sequentially from the database all continuous seismic data for the desired station, and for each extracted (2-hour) file, invokes the correlator which performs stepwise comparison of the template to time windows of the continuous data.

4) Using the output cross-correlation parameters, execute a second C program that searches for correlation values above a user-defined threshold and extracts a user-defined segment of the continuous data when a detection has been found, saving it to disk as a SAC format file.

Ten full waveform templates of 30 seconds after the $\mathrm{P}$ wave arrival and another 10 templates of 12 seconds of S coda were cut from the sequence catalog events exhibiting high signal to noise ratio. 
The PDAR array element used for this process was installed by the Airforce Technical Applications Center (AFTAC) in 1997, so the cross-correlation scans were possible to execute over two decades of continuous digital data, for both the 10 full waveform templates and the ten S-wave coda templates 


\section{Results and Discussion}

\subsection{Seismic Array Locations}

Using the parameters provided by the MBMG in the Hypoinverse code, I was able to produce the earthquake locations plotted in Figure 4.1.1. The calculated locations of the 58 events are shown in red overlying the MBMG's catalog locations in blue. Many of the events are colocated, and the error between my locations and the catalog locations are minimal. The ability to reproduce the catalog events allows for the use of the catalog locations as ground truth to compare the locations derived from the array data.
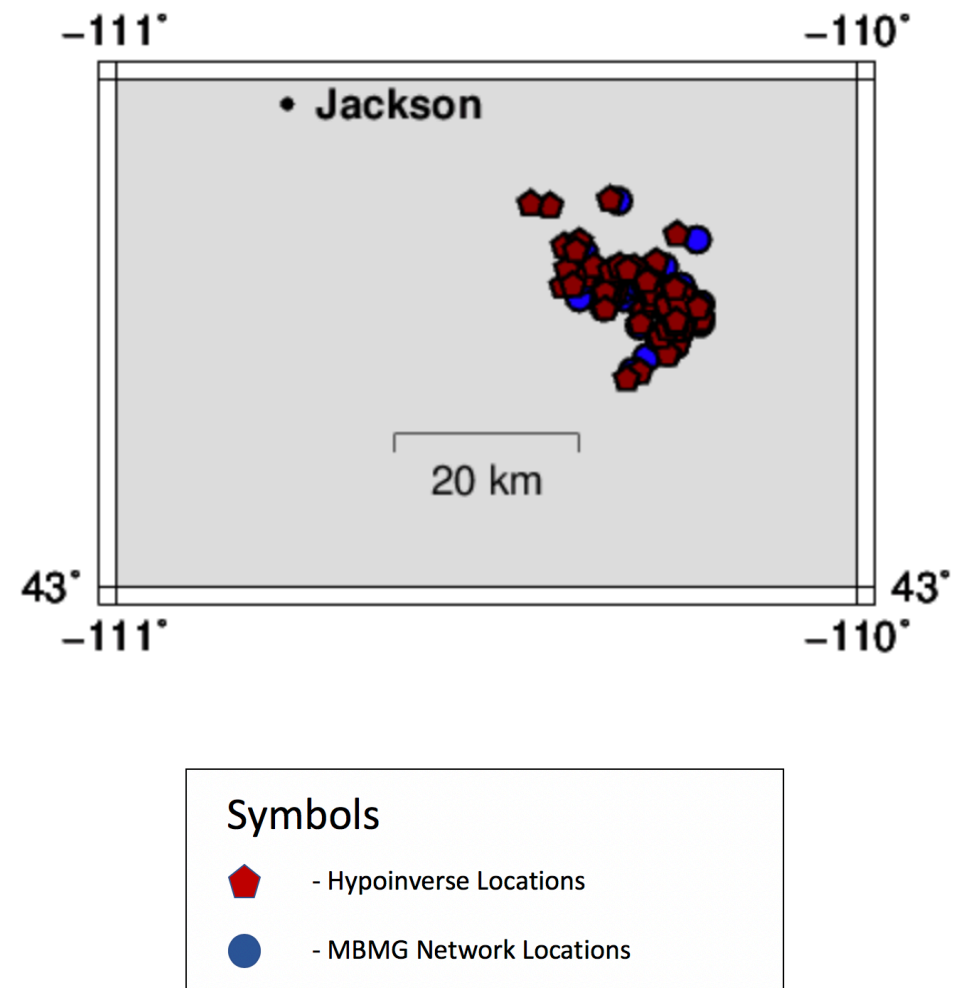

Figure 4.1.1: Network Location Validation

Using the parameters from the MBMG we were able to verify the earthquake locations reported by the MBMG. Our results are shown in red, while the reported locations are shown in blue. 
The seismic array methods implemented in this study produced two different locations for each event. The first series of locations used the average velocity calculated for individual events to determine the distance between the array and the source. Figure 4.1.2 shows the results of this location method.

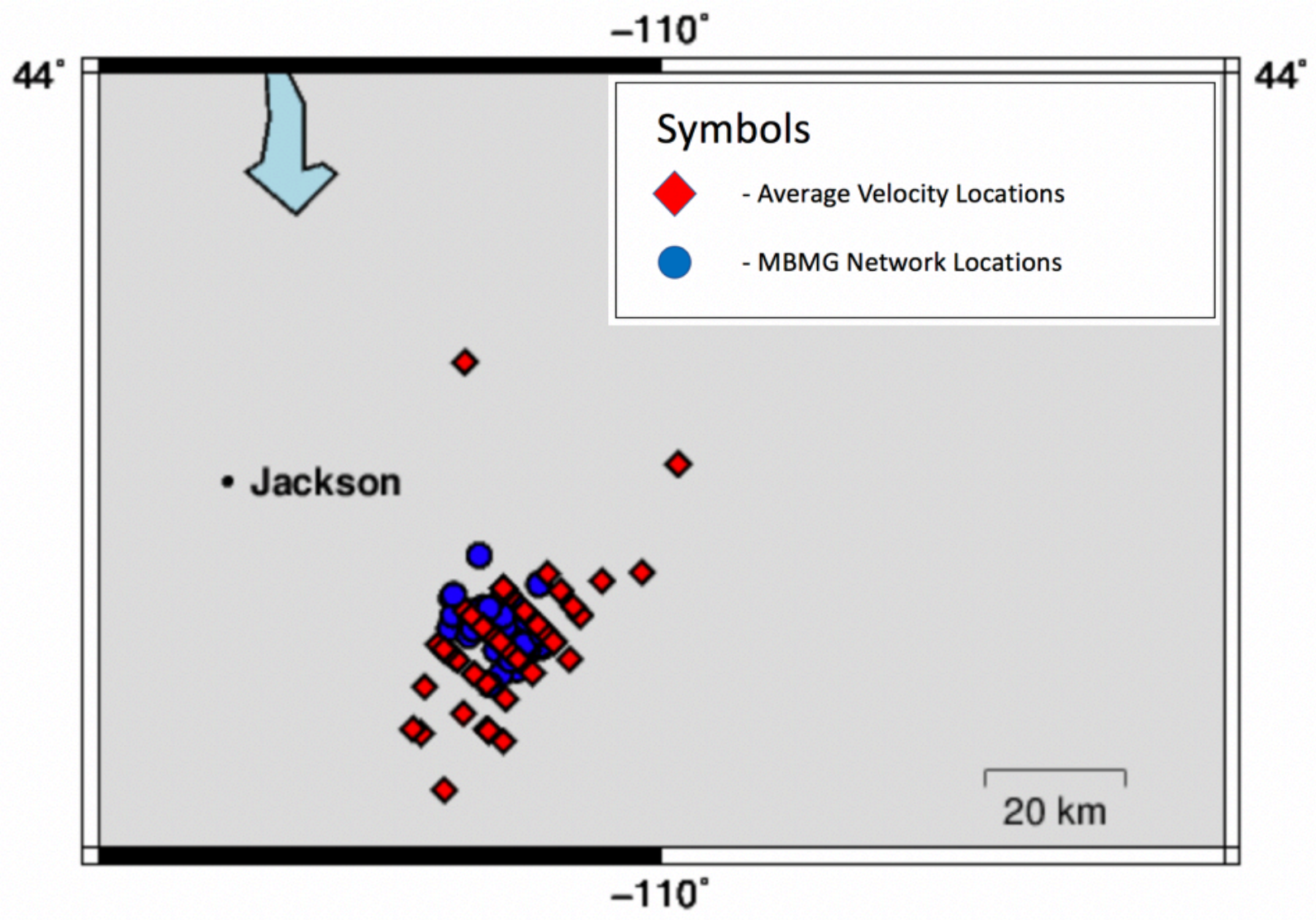

Figure 4.1.2: Average Velocity Method Locations

The average velocity method produces accurate distances from the array to the source with a wider spread in azimuths compared to the known event locations in blue.

The array locations using the average velocity method have a wider range of azimuths than the known locations and are linearly grouped by back azimuths determined during the F-K analysis. The locations are fairly accurate in the distance between the array and the source resulting in an average epicentral error of $22.7 \mathrm{~km}$. If I remove the two outliers to the north, the 
average location error decreases to $10.8 \mathrm{~km}$. This error is larger than desired and necessitated the use of other methods to determine the array locations in an effort to produce more accurate results.

The second method utilized to determine event locations from the array data uses velocities calculated from the wavenumber output during the BBFK analysis in order to calculate the distance between the array and the event. Figure 4.1.3 shows the array locations for the wavenumber method.

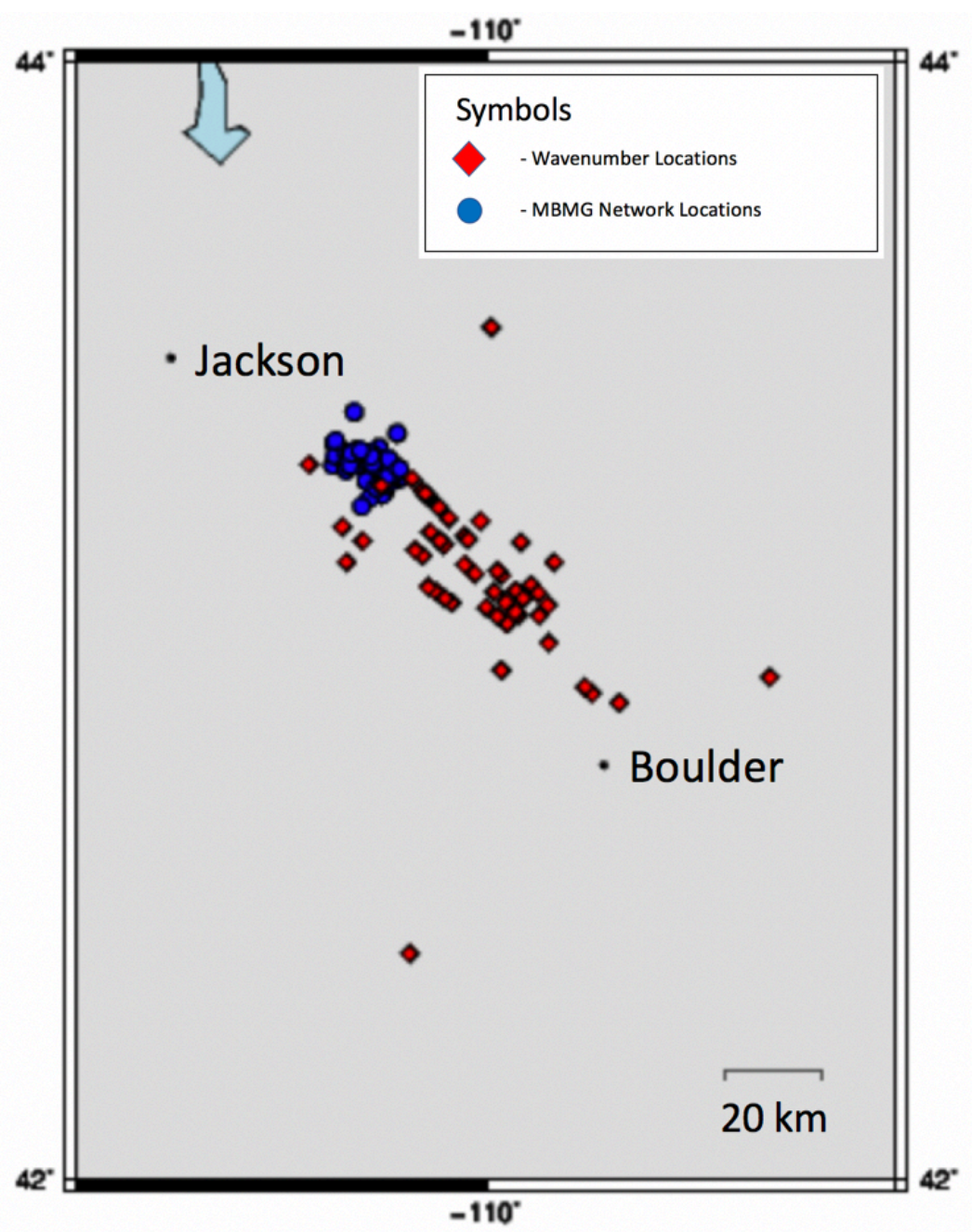

Figure 4.1.3: Wavenumber Method Locations

The array locations using the wavenumber method plot closer to the array than the known locations. 
The wavenumber method array locations have a larger variation in distance from the known location and the average velocity method but have a narrower azimuth range than the average velocity method. The epicentral error is significantly increased due to the variation in distance, increasing from just under $23 \mathrm{~km}$ up to an average of $43.9 \mathrm{~km}$. Removing the outliers with anomalous azimuths, the error decreases to an average of $30.5 \mathrm{~km}$.

The average velocity method of determining the distance from the array to the epicenter of an event provides a larger degree of accuracy compared to the wavenumber method, but the error could be the result of a decrease in the signal to noise ratio and therefore be related to the event's magnitude. Figures 4.1.4 and 4.1.5 plot the epicentral error of the average velocity method relative to magnitude and then signal to noise ratio.

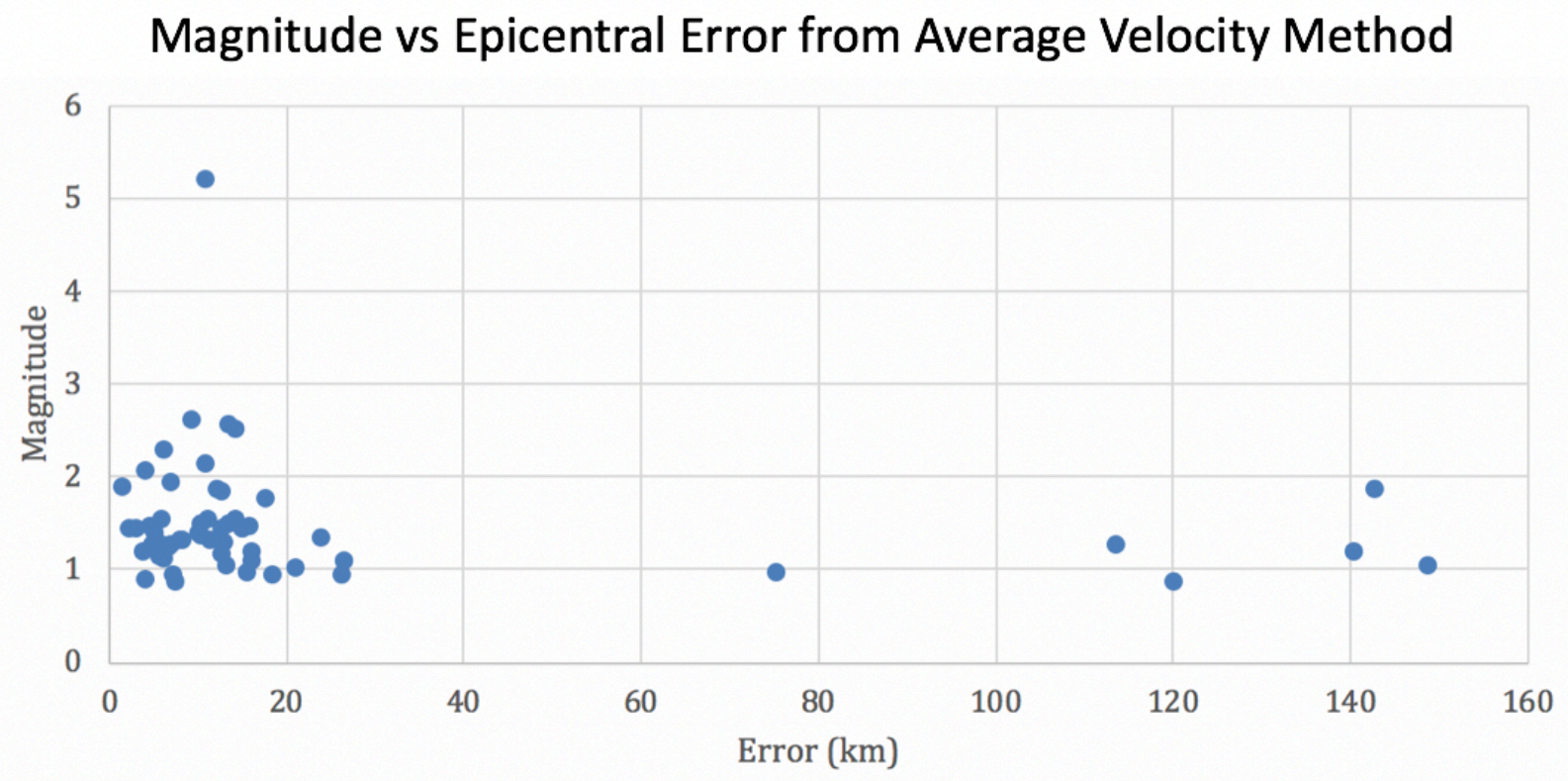

Figure 4.1.4: Magnitude vs Epicentral Error from Average Velocity Method The likelihood of a larger epicentral error increases if an events magnitude lies below 2 ML. 


\section{Signal to Noise Ratio vs Epicentral Error from Average Velocity Method}

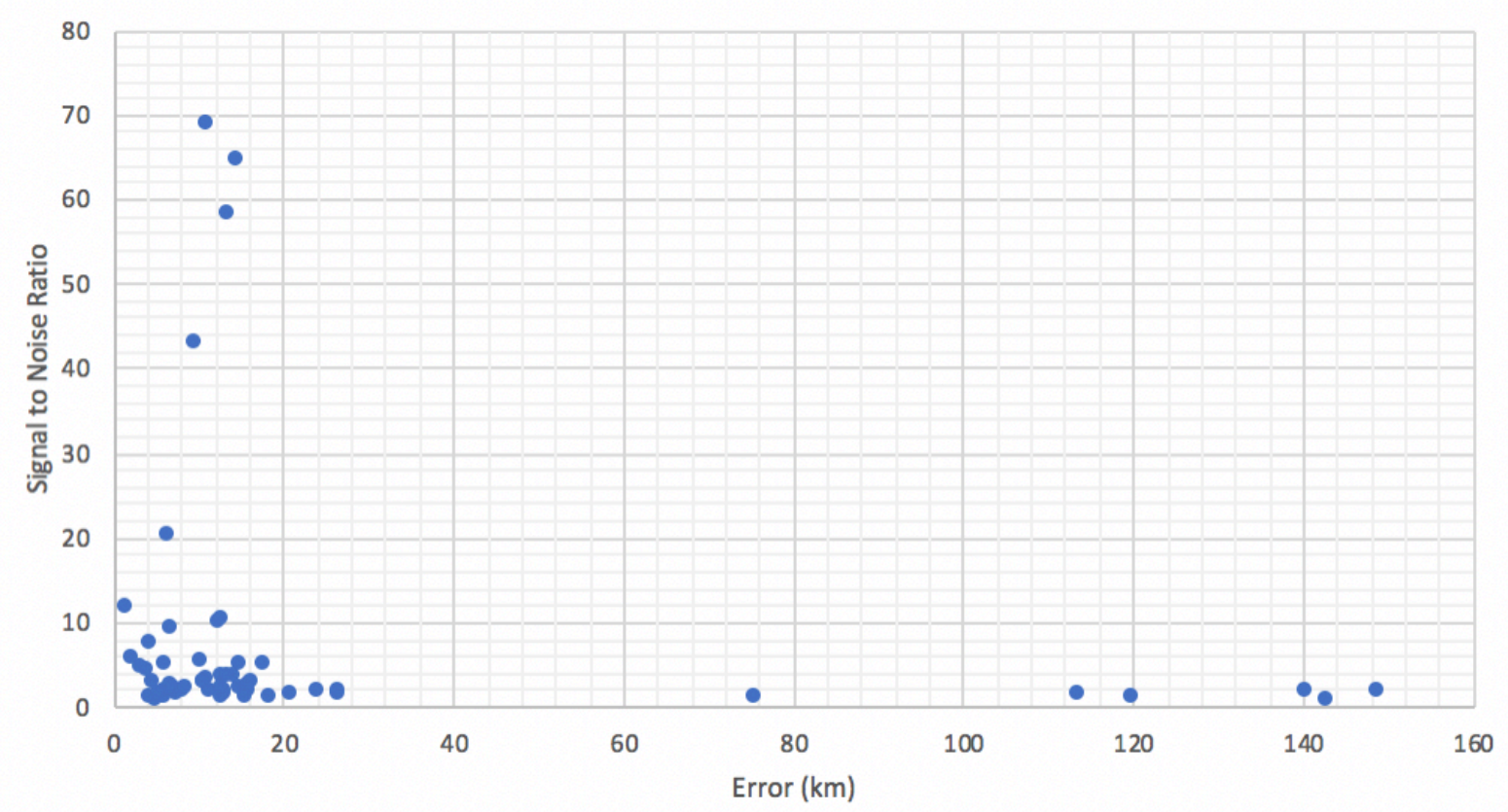

Figure 4.1.5: Signal to Noise Ratio vs Epicentral Error from Average Velocity Method Events with signal to noise ratios less than 3 are more likely to have a larger epicentral error.

The magnitude and signal to noise ratio of an earthquake tend to correlate well as a lower magnitude event tends to have a lower signal to noise ratio. This relationship can be seen in Figure 4.1.4 and 4.1.5, where the likelihood of a larger epicentral error is shown for events with magnitudes smaller than $2 \mathrm{ML}$ and signal to noise ratios less than 3 . However, there seems to be little evidence for a direct relationship between lower magnitudes or poor signal to noise ratios and epicentral error.

The observation in Figure 4.1.2, that the distances from the array to the event are fairly accurate but the azimuths from the array have a large range, reveal the largest source of error in the location calculations is the azimuth. Figure 4.1.6 illustrates the increase in epicentral error as the angle from the known azimuth of 313.5 degrees increases. 


\section{Back Azimuth vs Epicentral Error from Average Velocity Method}

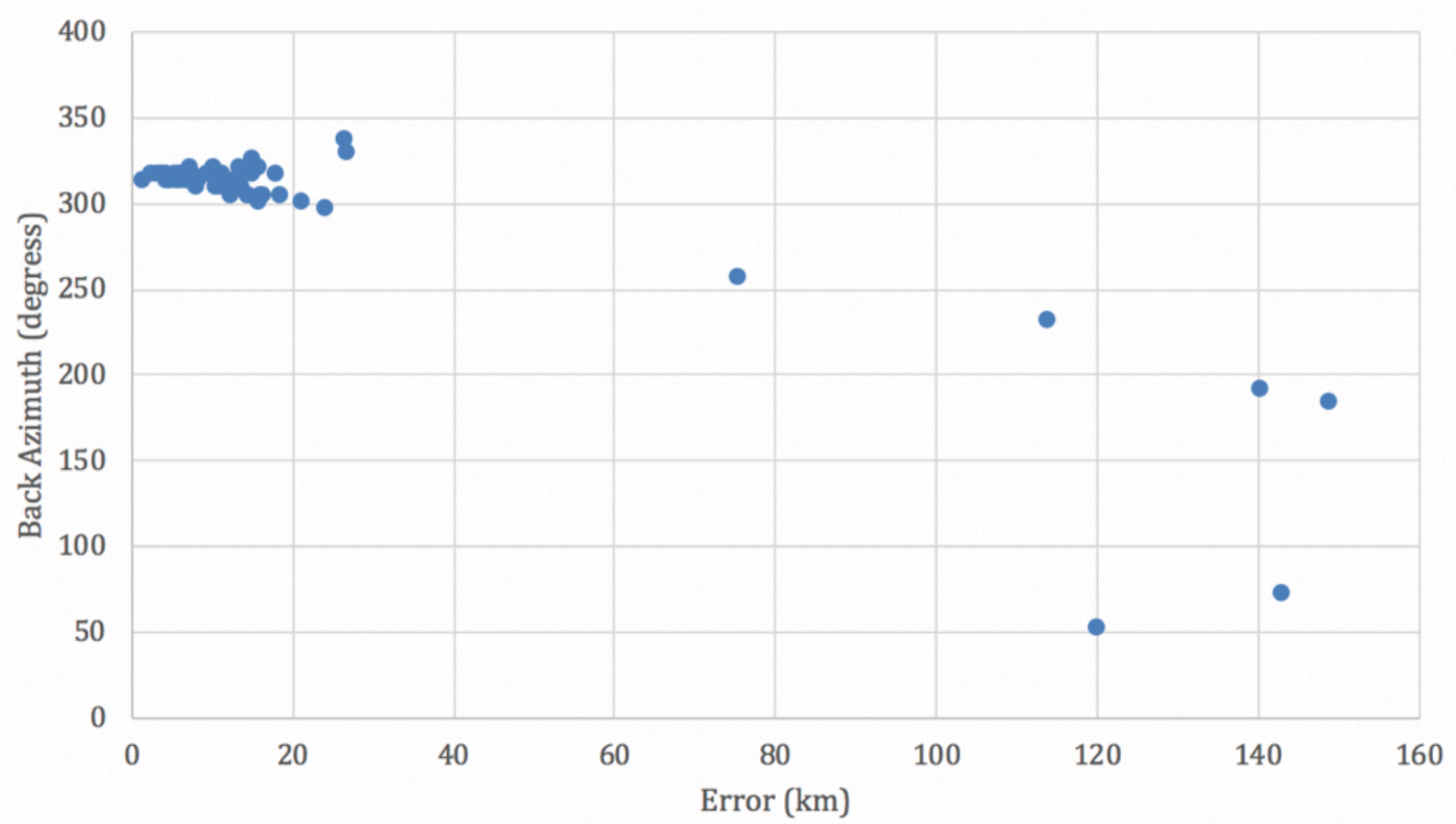

Figure 4.1.6: Back Azimuth vs Epicentral Error from Average Velocity Method

The increase in error is evident as the back azimuth diverges from the known back azimuth of 313.5 degrees.

Errors in back azimuth can be attributed to the nature of the array and the method as well as the velocity model used for the study. The back azimuths were calculated using BBFK analysis, a method that assumes a planar wave front arrives across the array. PDAR is located approximately $80 \mathrm{~km}$ from the epicenters of the seismic sequence, and therefore the wave fronts approaching the array are still arcs. This alone would introduce error to the array locations, but PDAR was designed to detect teleseismic events for AFTAC and is also less sensitive to local events. Finally, the velocity model used is not a 3D model and does not represent the local geology but rather a much larger area. These factors combined likely result in the errors found in the average velocity method for array locations. 
The seismic event locations as determined by the MBMG were plotted relative to the local geologic structures in the Jackson, WY region. Figure 4.1.7 displays the earthquakes and faults in the Gros Ventre region. The fault map in Figure 4.1.8 identifies the fault lines associated with Figure 4.1.7.

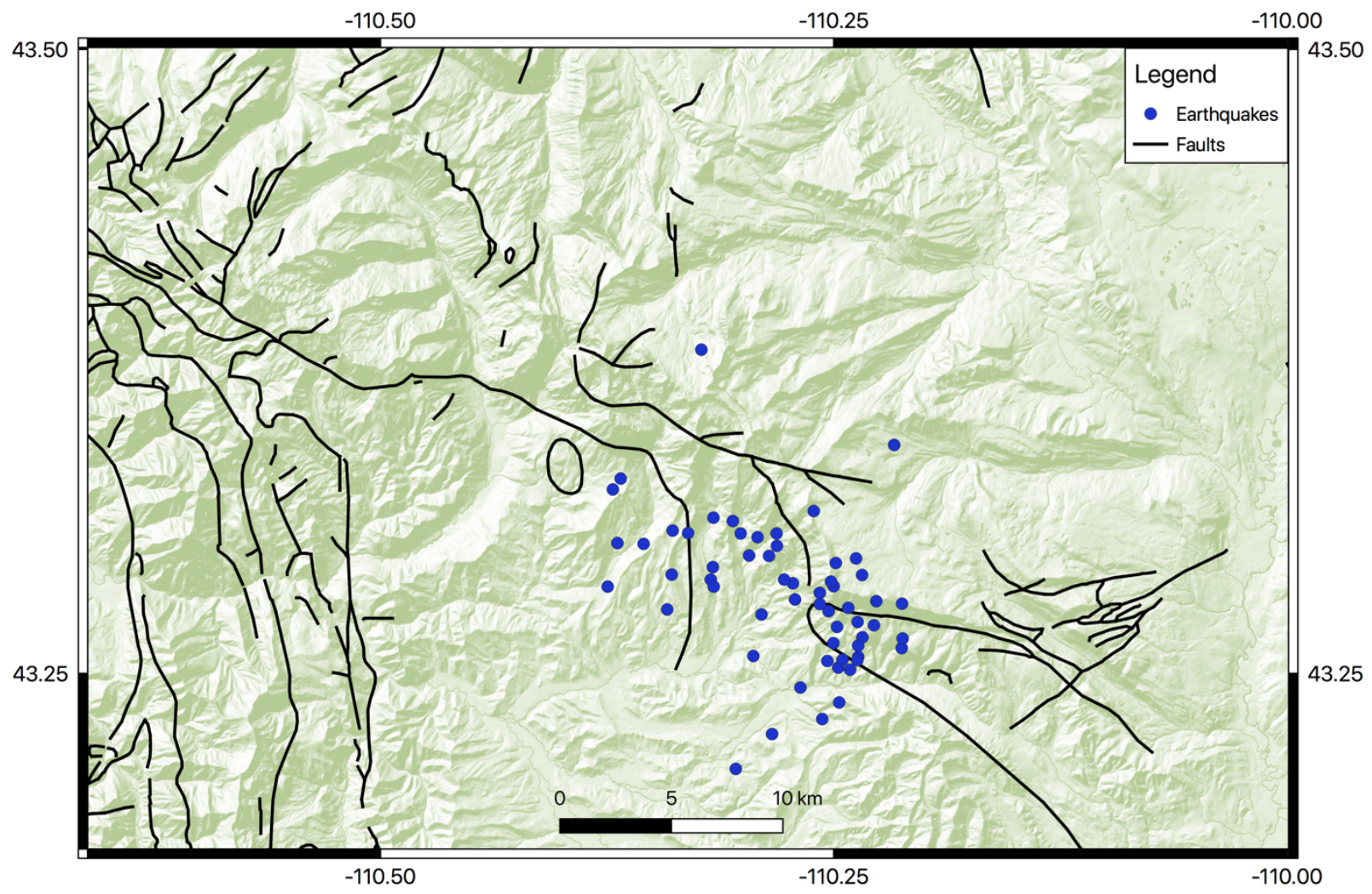

Figure 4.1.7: Earthquake Locations in the Gros Ventre Region

Earthquake locations are plotted relative to the local faults and show a wide spread coverage on the southeastern fault section. 


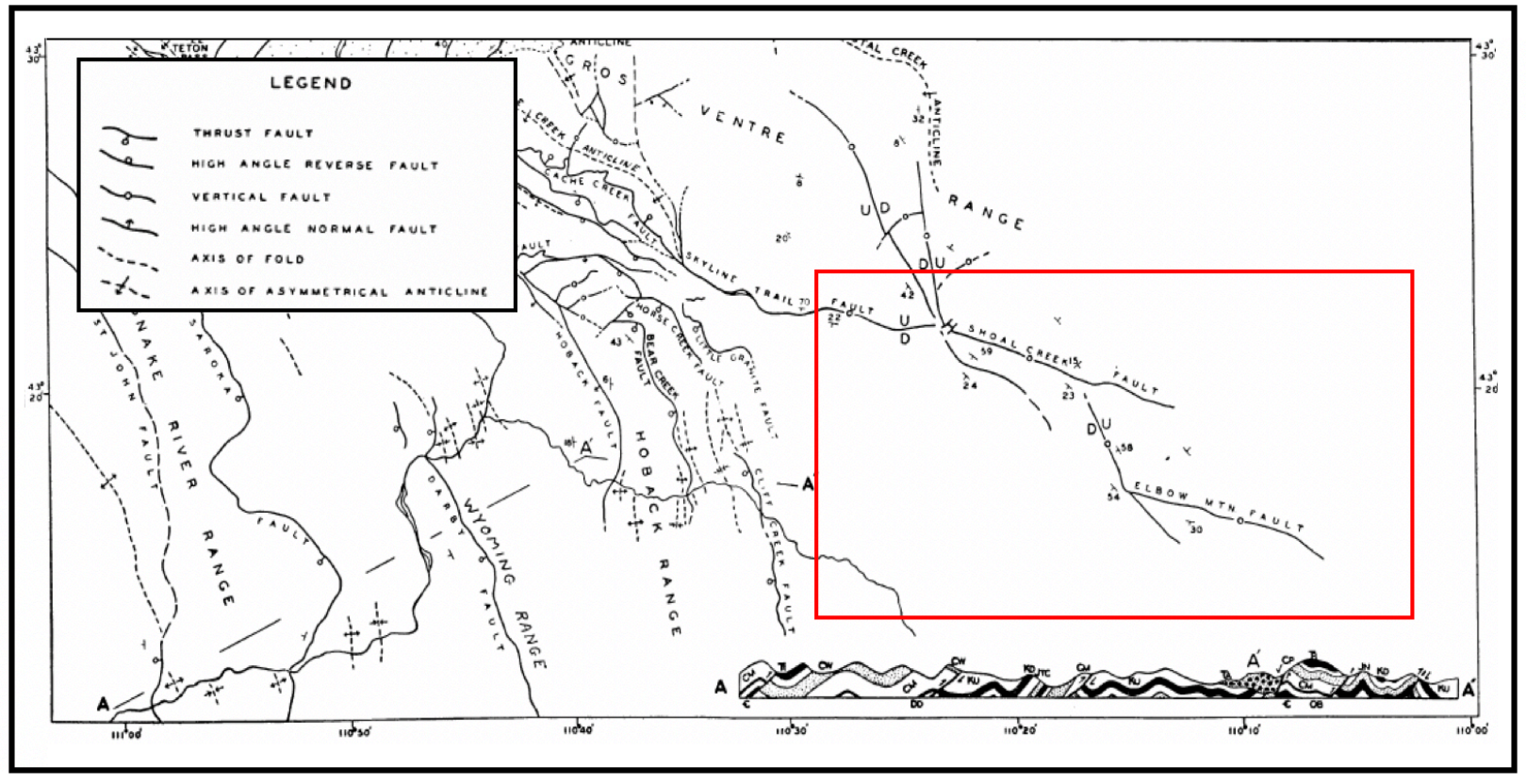

Figure 4.1.8: Fault Identification Map

The faults associated with the "Jackson Swarm" are highlighted in red. Modified from Nelson and Church (1943).

The locations of the events are clustered around the Elbow Mountain Fault and its western branch, the Jackson Peak Fault, and the Shoal Creek Fault and its western branch, the Pyramid Peak Fault. The events are roughly aligned in a northwest-southeast trend which follows the trend of the surrounding faults excluding the north-south trending Pyramid Peak Fault. The largest event in the sequence or swarm has a moment tensor plot (Figure 4.1.9). The two possible fault orientations are shown in the figure, but considering the known trends of the geologic features the normal fault strike is 335 degrees. 


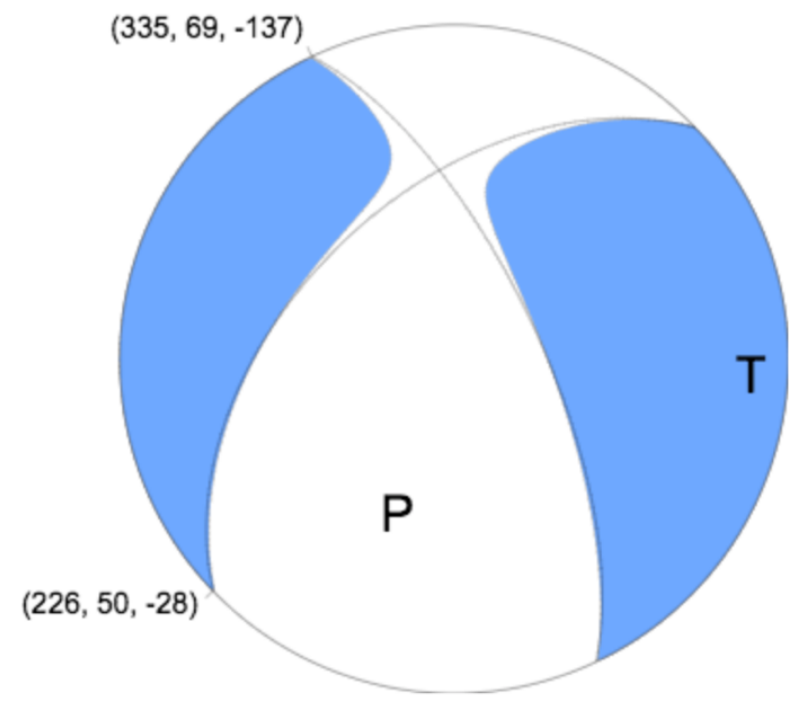

Figure 4.1.9: Moment Tensor

The moment tensor plots the two possible fault planes for the 5.2ML event and displays normal fault motion.

The 58 events in the sequence were plotted by magnitude in Figure 4.1 .10 and show a cluster of 1ML to $3 \mathrm{ML}$ events on the Jackson Peak Fault with the largest magnitude event lying to the southwest of the fault. To determine if the sequence migrated along the fault system, all of the events were grouped by month and plotted (Figure 4.1.11). The resultant map indicates that migration of deformation did not occur in an identifiable pattern. 


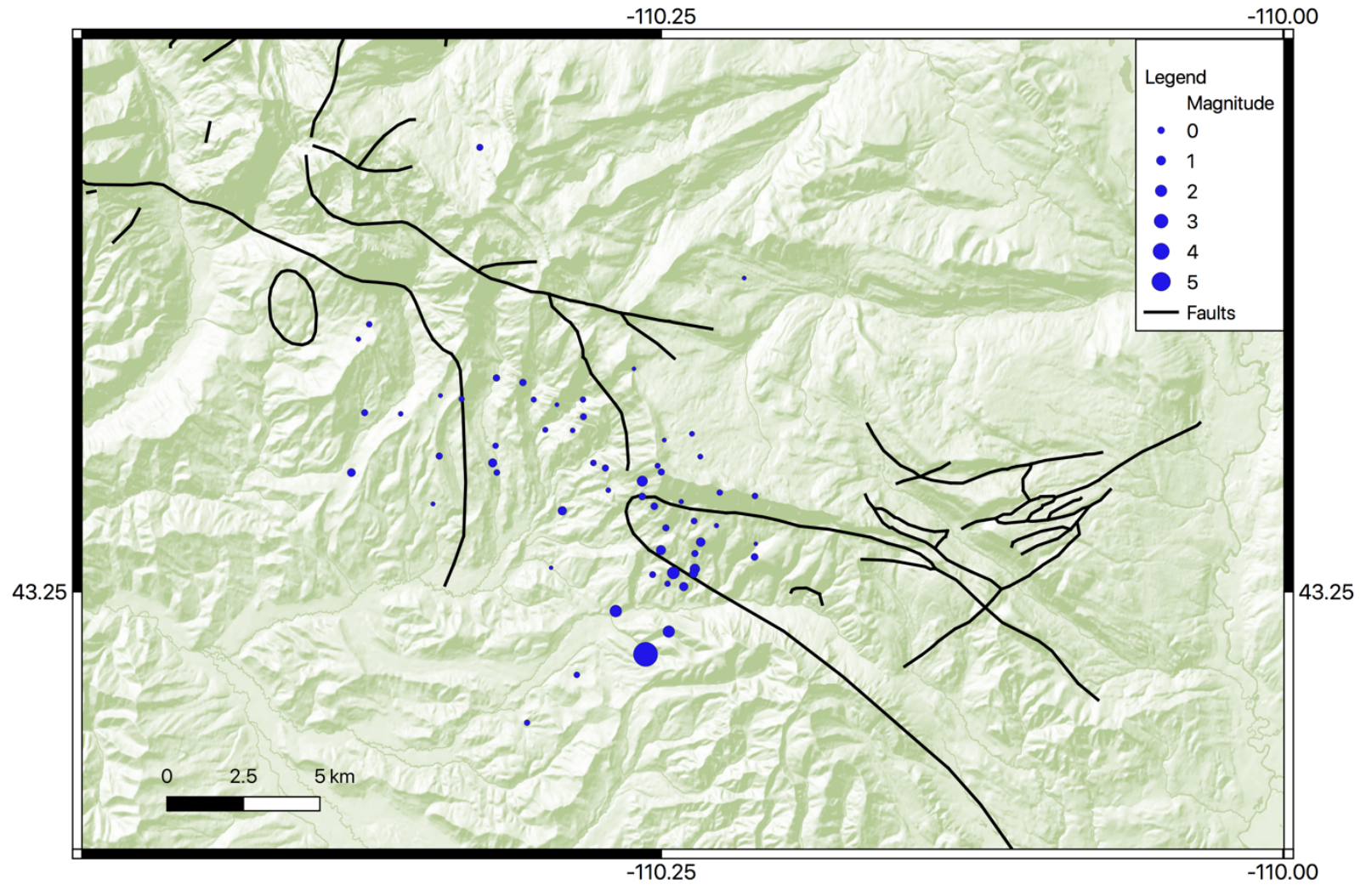

Figure 4.1.10: Event Magnitudes Map

The magnitudes for the events of the "Jackson Swarm" are shown relative to the local fault system. 


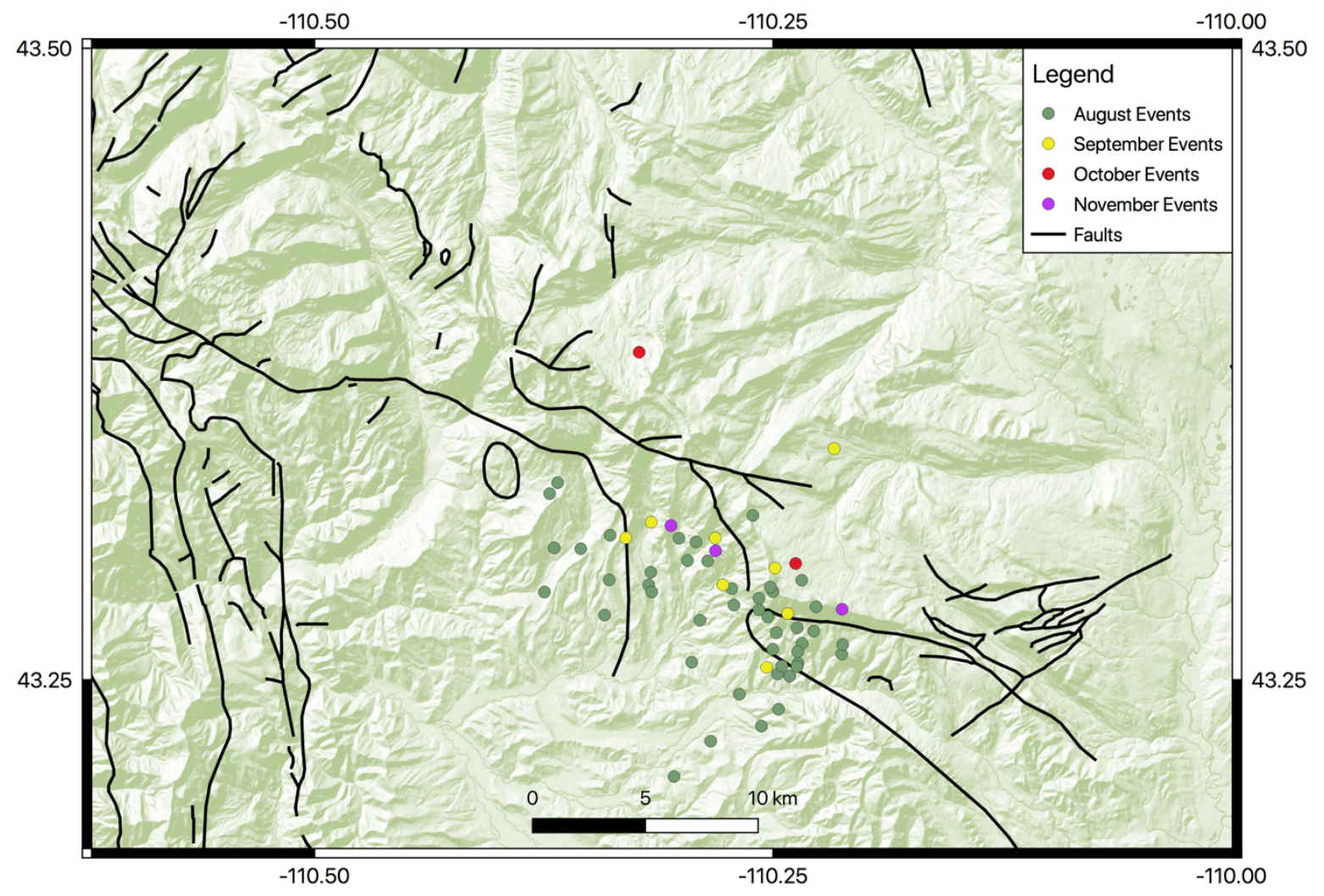

Figure 4.1.11: Event Migration Map

The events were mapped by month of occurrence but were determined to not have migrated along fault structures in an identifiable pattern.

\subsection{Cross-Correlation Swarm Reoccurrence Scan}

Almost two decades of continuous seismic data, spanning from 1997 to 2017, was scanned using 20 unique templates in an effort to determine if the seismic sequence near Jackson is a reoccurring swarm. The scan produced two uncatalogued events during the year of the swarm, but no recurring seismicity before 2016 .

The first template was S coda cut from an event on 08/27/16 at 17:34 and identified itself, a cataloged event, and an unrecorded event on 08/23/16 at 05:17:49 (Figure 4.2.1). The 
similarities between the template event and the two identified events can be observed in Figure 4.2.1 as well.
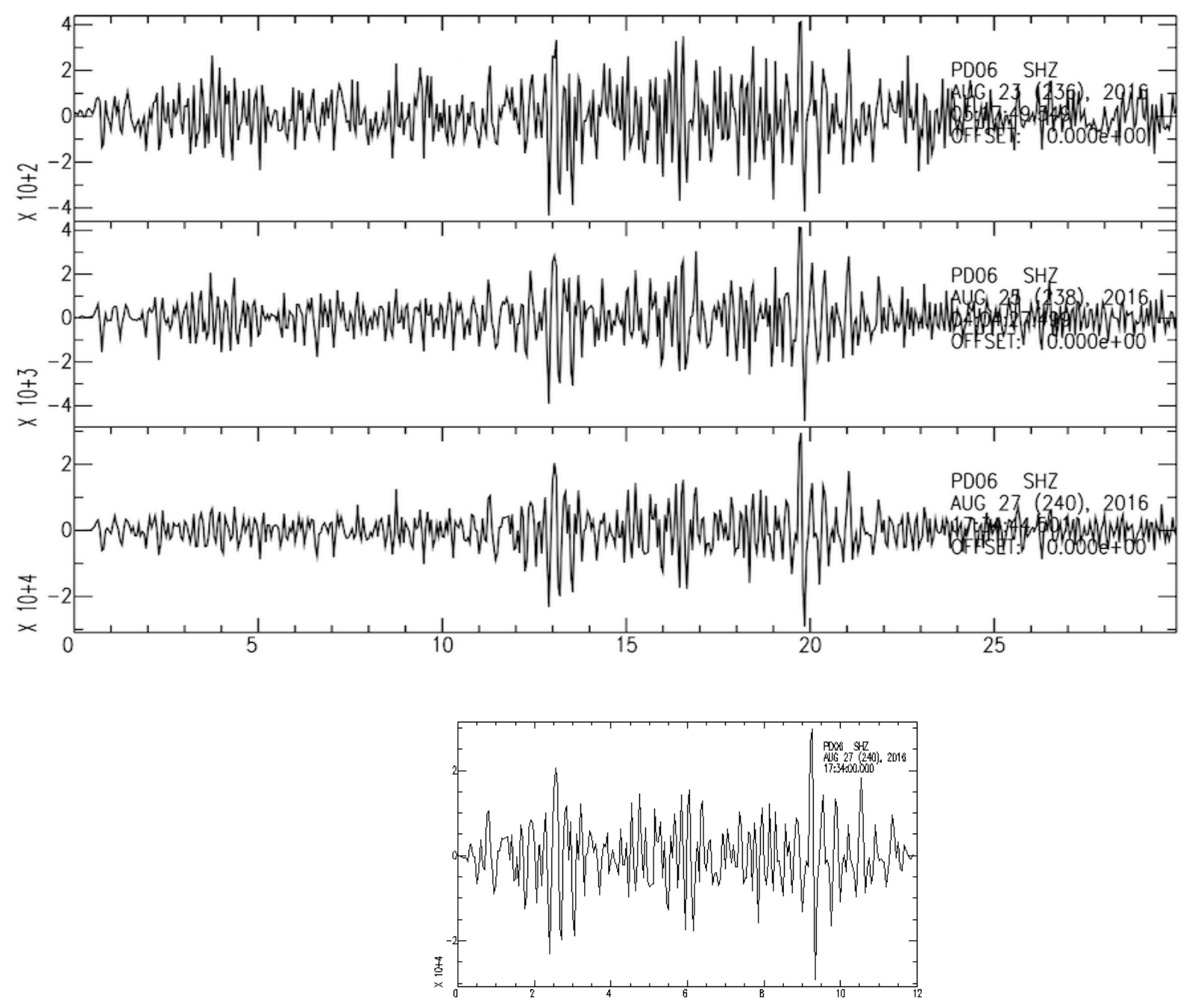

Figure 4.2.1: Template 1 Cross-Correlation Results

The 12-second-long template at the bottom identified an uncatalogued event within the swarm year, an identified event, and itself during the cross-correlation scan.

The second template is a full waveform template of an event on $08 / 27 / 16$ at $23: 43$ that produce an unidentified event as well as itself (Figure 4.2.2). The new event also occurred during the year of the swarm on 08/28/16 at 07:11:26. 

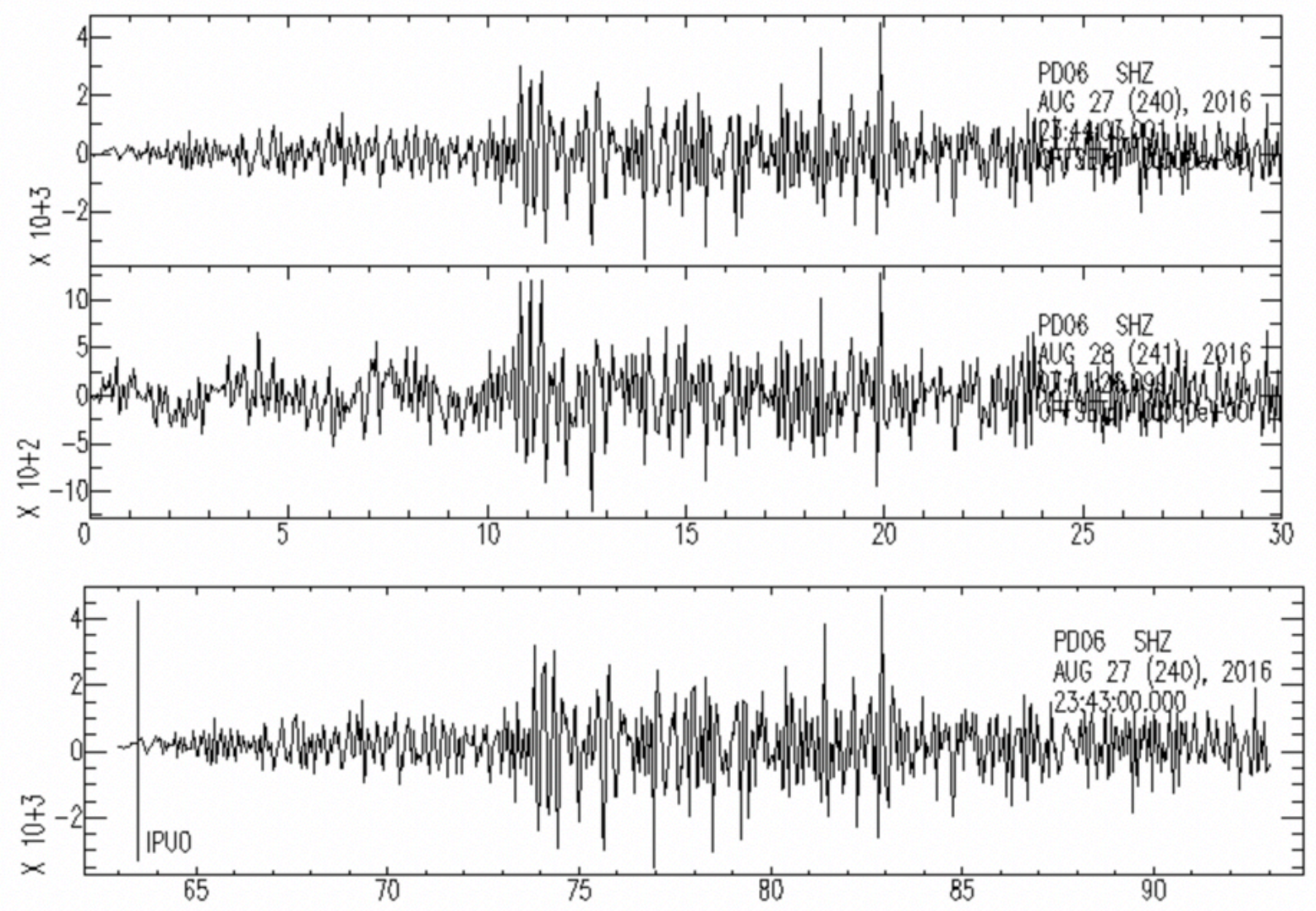

Figure 4.2.2: Template 2 Cross-Correlation Results

The full waveform template at the bottom identified itself and an uncatalogued event in the year of the swarm.

The lack of repeating events during the duration of the cross-correlation scan fails to support the possibility of seismic swarm behavior. Swarms differ from seismic sequences not only in their tendency for reoccurrence but their distribution of magnitude over time. The magnitude of swarm events builds over time and then tapers off while sequences can have foreshocks after which a main shock occurs creating a spike in magnitude early in the series. The aftershocks then decrease in magnitude. The magnitude of events over time in the "Jackson 
Swarm" are plotted in Figure 4.2.3 and show the characteristics of a seismic sequence's main shock - aftershock distribution of magnitudes over time.

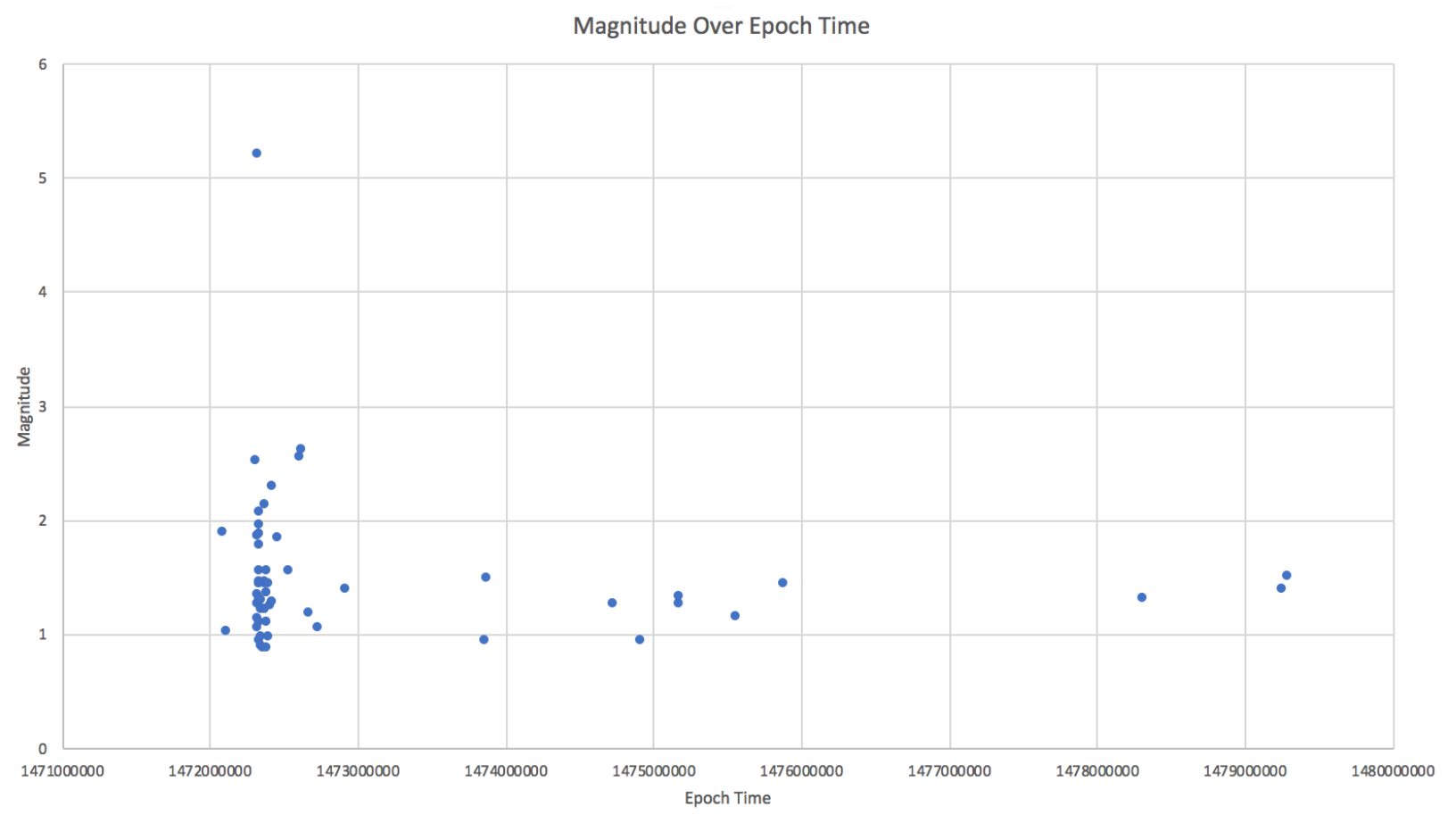

Figure 4.2.3: Event Magnitudes Over Epoch Time

The magnitude of events during the "Jackson Swarm" peaks early in the series and tapers off over time. This is indicative of a main shock - aftershock sequence. 


\section{Conclusions}

Determining the accuracy of event locations utilizing a seismic array is necessary in order to determine the validity of their usefulness in varying capacities to scientists. Larger errors in location accuracy may be permissible in certain studies while the results could be meaningless in others. The two methods shown to determine array locations using data from PDAR have varied epicentral errors. The average velocity method was deemed superior to the wavenumber method with a third of the error that is present in the latter method. Removing outliers in the data produces an error less than $11 \mathrm{~km}$.

While not ideal for detailed studies, the error is acceptable in studies trying to identify areas of seismological interest or determine regions subjected to mining explosions or nuclear tests. The accuracy of the locations can likely be improved by implementing a 3D local velocity model of the Jackson, Wyoming region and accounting for the arc in the wave front arriving at the array.

The location of the seismic sequence is associated with the Gros Ventre's southwestern faults that have a northwest-southeast trend. The largest event displays normal fault motions on a northwest-southeast striking fault. After mapping events by month, migration of deformation was not observed.

The cross-correlation scan of the continuous waveform data from PDAR produced two events that were not in our earthquake catalog and helped definitely determined that the "Jackson Swarm" is in fact a main shock - aftershock sequence rather than a swarm. Therefore, there is no reoccurrence interval or possibility of mitigating landslide hazards in the Jackson, Wyoming region. 


\section{References}

Aster, R., and Rowe, C., 2000, Automatic phase pick refinement and similar event association in large seismic datasets, Modern Approaches in Geophysics, vol. 18

Braile, L. W., Smith, R. B., Keller, G. R., Welch, R. M., and Meyer, R. P., 1974, Crustal structure across the Wasatch front from detailed seismic refraction studies, Journal of Geophysical Research, vol. 79, no. 17, p. 2669 - 2677

Brumbaugh, D. A., 2001, The 1994 Draney Peak, Idaho, earthquake sequence: focal mechanisms and stress field inversion, M.S. Thesis, University of Utah, Salt Lake City, Utah, pp. 157

Carroll, A. R., Chetel, L. M., and Smith, M. E., 2006, Feast to famine: Sediment supply control on Laramide basin fill, Geology, vol. 34, no. 3, p. 197 - 200

Dorr, J. A., Jr., 1952, Early Cenozoic stratigraphy and vertebrate paleontology of the Hoback, Basin, Wyoming, Bulletin of the Geologic Society of America, vol. 63, p. 59 - 94

Dorr, J. A., Jr., Spearing, D. R., Steidtmann, J. R., 1997, Deformation and deposition between a foreland uplift and an impining thrust belt thrust belt: Hoback Basin, Wyoming, Geological Society of America Special Paper 177, p. 82

Fan, M. and Carrapa, B., 2014, Late Cretaceous-early Eocene Laramide uplift, exhumation, and basin subsidence in Wyoming: Crustal responses to flat slab subduction, Tectonics, vol. 33, p. $509-529$ 
Frost, C. D., Frost, B. R., Chamberlain, K. R., and Hulsebosch, T. P., 1998, The Late Archean history of the Wyoming province as recorded by granitic magmatism in the Wind River Range, Wyoming, Precambrian Research, vol. 89, p. 145 - 173

Got, J. L. et al., 1994, Deep fault plane geometry inferred from multiplet relative relocation beneath the south flank of Kilauea, Journal of Geophysical Research, vol. 99, p. 15,375 - 15,386

Hagen, E. S., Shuster, M.W., and Furlong, K.P., 1985, Tectonic loading and subsidence of intermontane basins: Wyoming foreland province, Geology, vol. 13, p. 585 - 588

Harjes, H. P. and Henger, M., 1973, Array-Seismologie, Z. Geophysics, vol. 39, p. 865 - 905

Heller, P. L. and Liu, L., 2016, Dynamic topography and vertical motion of the U.S. Rocky Mountain region prior to and during the Laramide orogeny, GSA Bulletin, vol. 128, no. 5/6, p. $973-988$

Keefer, W. R., 1970, Structural geology of the Wing River Basin, Wyoming, U.S. Geological Survey Professional Paper 495-D, pp. 35

Klein, F. W., 2014, User's guide to HYPOINVERSE-2000, a Fortran program to solve for earthquake locations and magnitudes, U.S. Geological Survey Open-File Report 02 - 171, pp. 148 
MacCarthy, J. K. and Rowe, C. A., 2014, Pisces: A practical seismological database library in Python, Seismology Research Letters, vol. 85, no. 4, p. $905-911$

Nelson, V. E. and Church, V., 1943, Critical structures of the Gros Ventre and northern Hoback Ranges, Wyoming, The Journal of Geology, vol. 51, no. 3, p. 143 - 166

Pechmann, J. C., Brumbaugh, D. A., Nava S. J., Skelton T. G., Fivas G. P., Arabasz W. J., and Jackson S. M., 1997, The 1994 Draney Peak, ID, earthquake and its aftershocks, EOS Trans. AGU 78, no. 46 (Suppl.), F480

Rost, S. and Thomas, C., 2002, Array seismology: methods and applications, Reviews of Geophysics, vol. 40, p. 2-1 -2-27

Rowe, C., 2000, Correlation-based phase pick correction and similar earthquake family identification in large seismic waveform catalogs, Ph.D. Thesis, New Mexico Institute of Mining and Technology, Socorro

Rowe, C.A., Aster, R.C., Borchers, B., and Young, C.J., 2002, An automatic, adaptive algorithm for refining phase picks in large seismic data sets, Bulletin of the Seismological Society of America, vol. 92, p. 1660 - 1674

Smithson, S. B., Brewer, J., Kaufman, S., Oliver, J., and Hurich, C., 1978, Nature of the Wind River thrust, Wyoming, from COCORP deep-reflection data and from gravity data, Geology, vol. 6 , p. $648-652$ 
Sparlin, M. A., Braile, L. W., and Smith, R. B., 1982, Crustal structure of the eastern Snake River Plain determined from ray trace modeling of seismic refraction data, Journal of Geophysical Research, vol. 87, p. $2619-2633$

Stankova, J., Bilek, S.L., Rowe, C.A., and Aster, R.C., 20018, Characteristics of the October 2005 microearthquake swarm and reactivation of similar event seismic swarms over decadal time periods near Socorro, New Mexico, Bulletin of the Seismological Society of America, vol. 98, p. $93-105$

Steidtmann, J. R. and Middleton, L. T., 1991, Fault chronology and uplift history of the southern Wind River Range, Wyoming: Implications for Laramide and post-Laramide deformation in the Rocky Mountain foreland, GSA Bulletin, vol. 103, p. 472 - 485

Stevens, A. L., Balgord, E. A., and Carrapa, B., 2016, Revised exhumation history of the Wind River Range, WY, and its implications for Laramide tectonics, Tectonics, vol. 35, p. 1121 - 1136

Waldhauser, F. and Ellsworth, W. L., 2000, A double-difference earthquake location algorithm: Method and application to the Northern Hayward Fault, California, Bulletin of the Seismological Society of America, vol. 40, p. 1353 - 1368 


\section{Appendix}

Table A1: Earthquake Information

Location, depth, and magnitude are listed for each event in the seismic sequence.

\begin{tabular}{|c|c|c|c|c|}
\hline Time & Latitude & Longitude & Depth & Magnitude \\
\hline $8 / 25 / 164: 04$ & 43.2736667 & -110.2898333 & 7.31 & 1.88 \\
\hline 8/25/16 9:27 & 43.2693333 & -110.2278333 & 6.01 & 1.02 \\
\hline $8 / 27 / 1617: 34$ & 43.2366 & -110.2471 & 4.53 & 2.51 \\
\hline $8 / 27 / 1620: 47$ & 43.2226 & -110.3593 & 12.3 & 5.2 \\
\hline $8 / 27 / 1620: 55$ & 43.2876667 & -110.3178333 & 6.65 & 1.85 \\
\hline $8 / 27 / 1621: 28$ & 43.2848333 & -110.3161667 & 6.08 & 1.33 \\
\hline $8 / 27 / 1621: 34$ & 43.2523333 & -110.2475 & 6.03 & 1.26 \\
\hline $8 / 27 / 1621: 35$ & 43.3238333 & -110.3718333 & 6.02 & 1.05 \\
\hline $8 / 27 / 1622: 22$ & 43.2796667 & -110.2713333 & 6 & 1.12 \\
\hline $8 / 27 / 1622: 35$ & 43.2601667 & -110.2125 & 5.99 & 1.54 \\
\hline $8 / 27 / 1622: 50$ & 43.2515 & -110.241 & 6.02 & 1.87 \\
\hline $8 / 27 / 1623: 11$ & 43.2686667 & -110.2481667 & 6 & 1.45 \\
\hline $8 / 27 / 1623: 38$ & 43.2645 & -110.2341667 & 6 & 1.94 \\
\hline $8 / 27 / 1623: 43$ & 43.2621667 & -110.2501667 & 6.01 & 2.06 \\
\hline $8 / 27 / 1623: 49$ & 43.302 & -110.3548333 & 5.99 & 1.09 \\
\hline $8 / 27 / 1623: 55$ & 43.2256667 & -110.284 & 5.87 & 1.3 \\
\hline $8 / 28 / 160: 06$ & 43.2848333 & -110.3746667 & 6.08 & 1.77 \\
\hline $8 / 28 / 160: 12$ & 43.3023333 & -110.3693333 & 5.98 & 1.43 \\
\hline $8 / 28 / 160: 17$ & 43.2926667 & -110.3166667 & 6.07 & 1.27 \\
\hline
\end{tabular}




\begin{tabular}{|c|c|c|c|c|}
\hline $8 / 28 / 160: 28$ & 43.285 & -110.25 & 6.03 & 1.44 \\
\hline $8 / 28 / 161: 56$ & 43.3046667 & -110.292 & 6.1 & 0.93 \\
\hline $8 / 28 / 162: 22$ & 43.3061667 & -110.3013333 & 15.95 & 1.2 \\
\hline $8 / 28 / 162: 45$ & 43.3073333 & -110.3388333 & 6.06 & 0.96 \\
\hline 8/28/16 3:19 & 43.3281667 & -110.3675 & 5 & 1.29 \\
\hline $8 / 28 / 164: 56$ & 43.264 & -110.212 & 6.02 & 0.88 \\
\hline $8 / 28 / 165: 45$ & 43.3151667 & -110.261 & 6.06 & 0.87 \\
\hline $8 / 28 / 169: 23$ & 43.2868333 & -110.2515 & 6 & 1.2 \\
\hline $8 / 28 / 1610: 33$ & 43.2566667 & -110.2365 & 4.61 & 2.13 \\
\hline $8 / 28 / 1611: 14$ & 43.2611667 & -110.2365 & 6.02 & 1.43 \\
\hline $8 / 28 / 1611: 56$ & 43.2896667 & -110.3393333 & 6.02 & 1.45 \\
\hline $8 / 28 / 1612: 10$ & 43.2973333 & -110.2966667 & 6.22 & 1.2 \\
\hline $8 / 28 / 16$ 13:02 & 43.2971667 & -110.2856667 & 6 & 1.09 \\
\hline $8 / 28 / 1613: 15$ & 43.275 & -110.2528333 & 6.01 & 1.54 \\
\hline $8 / 28 / 1614: 37$ & 43.2706667 & -110.2368333 & 6.01 & 1.35 \\
\hline $8 / 28 / 16$ 15:41 & 43.257 & -110.2943333 & 6.01 & 0.87 \\
\hline $8 / 28 / 1616: 23$ & 43.2861667 & -110.2725 & 16.58 & 1.44 \\
\hline $8 / 28 / 1617: 07$ & 43.2756667 & -110.3418333 & 6 & 0.97 \\
\hline $8 / 28 / 1620: 53$ & 43.2116667 & -110.304 & 5.98 & 1.24 \\
\hline 8/28/16 23:04 & 43.2823333 & -110.2576667 & 5.64 & 2.28 \\
\hline $8 / 28 / 1623: 50$ & 43.279 & -110.2265 & 6 & 1.28 \\
\hline $8 / 29 / 169: 54$ & 43.2553333 & -110.237 & 6 & 1.84 \\
\hline $8 / 30 / 167: 27$ & 43.2778333 & -110.2576667 & 6.02 & 1.54 \\
\hline
\end{tabular}




\begin{tabular}{|l|l|l|l|l|}
\hline $8 / 31 / 162: 43$ & 43.2612 & -110.2566 & 5 & 2.6 \\
\hline $8 / 31 / 166: 11$ & 43.2663 & -110.232 & 5 & 2.6 \\
\hline $8 / 31 / 1620: 01$ & 43.2895 & -110.2343333 & 6.01 & 1.17 \\
\hline $9 / 1 / 1615: 51$ & 43.2763333 & -110.242 & 6 & 1.05 \\
\hline $9 / 3 / 1619: 18$ & 43.255 & -110.2535 & 6.02 & 1.38 \\
\hline $9 / 14 / 1616: 56$ & 43.3125 & -110.3163333 & 16.36 & 1.48 \\
\hline $9 / 14 / 1619: 48$ & 43.3063333 & -110.3303333 & 13.02 & 1.25 \\
\hline $9 / 24 / 1618: 13$ & 43.2943333 & -110.2488333 & 6.01 & 0.94 \\
\hline $9 / 26 / 1619: 33$ & 43.2876667 & -110.2773333 & 5.73 & 1.32 \\
\hline $9 / 29 / 1619: 23$ & 43.2596667 & -110.2455 & 3.46 & 2.46 \\
\hline $9 / 29 / 1621: 42$ & 43.3061667 & -110.2815 & 6.03 & 1.26 \\
\hline $10 / 4 / 166: 26$ & 43.2645 & -110.2418333 & 5.97 & 1.14 \\
\hline $10 / 8 / 161: 39$ & 43.2961667 & -110.2376667 & 6.05 & 1.14 \\
\hline $11 / 5 / 162: 20$ & 43.278 & -110.2123333 & 6 & 1.31 \\
\hline $11 / 16 / 161: 58$ & 43.3011667 & -110.2813333 & 6.06 & 1.39 \\
\hline $11 / 16 / 1613: 18$ & 43.3111667 & -110.3056667 & 6.04 & 1.49 \\
\hline
\end{tabular}


Table A2: Hypoinverse Command File

The command file sets the parameters needed to locate the events using the network stations used by the MBMG, in order to confirm the locations for the known earthquakes.

\begin{tabular}{|c|c|}
\hline LET 52322 & SEED Station Codes \\
\hline RMS 40.5024 & Residual Weighting \\
\hline ERR 0.10 & Standard Timing Error \\
\hline ERC 1.0 & RMS Weighting Factor \\
\hline POS 1.74 & P to S Ratio \\
\hline \multirow[t]{2}{*}{ REP T F } & Logs Events to Terminal, \\
\hline & Won't Print Unweighted Stations \\
\hline \multirow[t]{2}{*}{ JUN F } & Disable Distance Weighting in \\
\hline & $\mathrm{NWR}<\mathrm{MIN}=4$ \\
\hline MIN 4 & Minimum Number of Stations \\
\hline NET 0 & Regional Codes \\
\hline ZTR $6.0 \mathrm{~F}$ & Trial Depth \\
\hline D11 15036 & Initial Distance Weighting \\
\hline D1S 4752.04 .0 & Main Distance Weighting \\
\hline WET $1 . .5 .2 .1$ & Weights for P Weight Codes $0-3$ \\
\hline DAM 10.05 .00 .250 .80 .0160 .050 .6050 .999 .0 & Damping Controls \\
\hline CON 200.040 .001 & Convergence Controls \\
\hline SWT 0.6 & S Weight Factor \\
\hline \multicolumn{2}{|l|}{ Output Format } \\
\hline ERF T & Send Error Messages to Terminal \\
\hline TOP F & No Page Ejects \\
\hline
\end{tabular}




\begin{tabular}{|c|c|}
\hline LST 201 & Station List or Models in Print File \\
\hline KPR 2 & Medium Print Output Each Event \\
\hline H71 213 & Use Hypo71 Summary Format \\
\hline \multicolumn{2}{|l|}{ Station Data } \\
\hline \multicolumn{2}{|l|}{ TYP Read in stations: } \\
\hline STA 'Jackson.sta' & Read ASCII File of All Stations \\
\hline \multirow[t]{2}{*}{ FMC ‘all2000seed.fmc’ T 0} & Read Duration Magnitude Correction \\
\hline & History (This wasn't used.) \\
\hline \multicolumn{2}{|l|}{ Crustal Model } \\
\hline \multicolumn{2}{|l|}{ TYP Read in crustal model(s): } \\
\hline \multicolumn{2}{|l|}{ CRH 1 'DraneyPeakModel.crh' } \\
\hline DEL 1 'gey4.del' & This wasn't used. \\
\hline \multicolumn{2}{|l|}{ CRH 2 ‘DraneyPeakModelS.crh’ } \\
\hline DEL 2 'gey4.del' & This wasn't used. \\
\hline \multicolumn{2}{|l|}{ SAL 12} \\
\hline \multicolumn{2}{|l|}{ Duration Magnitude Settings } \\
\hline DUR -.81 $2.220 .00110,5 * 0,99991$ & Sets Eaton's New Magnitude Constants \\
\hline DU2 .005 40,.0006 350,.014 10 & Distance and Depth Terms for Eaton \\
\hline $\mathrm{FC1}$ 'D' 5 'EHZ' 'HHZ' 'BHZ' 'DPZ' & $\begin{array}{l}\text { Name and Components for Duration } \\
\text { Magnitude }\end{array}$ \\
\hline \multicolumn{2}{|l|}{ Choosing the Preferred Magnitude } \\
\hline $\begin{array}{l}\text { PRE 6, } 3039,1109,2109,4449,3009 \text {, } \\
4009\end{array}$ & Preferred Magnitudes \\
\hline Set Default Phase File & \\
\hline
\end{tabular}




TYP Hit enter or carriage-return to keep the test
filenames:
TYP (Also tests the phase file to use it's format)
PHS 'Jackson.phs'
FIL
Set Default Print File
PRT 'Jackson.prt'
PRT
Set Default Summary File File and Sets it's Format
SUM 'Jackson.sum'
SUM
Set Default Archive File
ARC 'Jackson.arc'
ARC


Table A3: P Wave and S Wave Signal to Noise Ratios

The signal to noise ratio for both $\mathrm{P}$ and $\mathrm{S}$ waves for each event is listed.

\begin{tabular}{|l|r|r|}
\hline \multicolumn{1}{|l|}{ Time } & \multicolumn{1}{l|}{ P Wave SNR } & \multicolumn{1}{l|}{ Wave SNR } \\
\hline $8 / 25 / 164: 04$ & 11.59395013 & 20.70990598 \\
\hline $8 / 25 / 169: 27$ & 1.503178484 & 2.549242054 \\
\hline $8 / 27 / 1617: 34$ & 64.58387771 & 153.1633786 \\
\hline $8 / 27 / 1620: 47$ & 6323.698495 & 11759.13794 \\
\hline $8 / 27 / 1620: 55$ & 0.88821819 & 1.607469297 \\
\hline $8 / 27 / 1621: 28$ & 1.765364721 & 4.608194518 \\
\hline $8 / 27 / 1621: 34$ & 0.903191338 & 2.014531985 \\
\hline $8 / 27 / 1621: 35$ & 1.669837655 & 3.743941561 \\
\hline $8 / 27 / 1622: 22$ & 1.148148539 & 3.009534469 \\
\hline $8 / 27 / 1622: 35$ & 3.34788134 & 6.547373015 \\
\hline $8 / 27 / 1622: 50$ & 9.961817599 & 15.86172724 \\
\hline $8 / 27 / 1623: 11$ & 2.795767874 & 8.278148591 \\
\hline $8 / 27 / 1623: 38$ & 9.311127933 & 28.09049748 \\
\hline $8 / 27 / 1623: 43$ & 7.492649685 & 22.66369906 \\
\hline $8 / 27 / 1623: 49$ & 1.378204858 & 3.396411964 \\
\hline $8 / 27 / 1623: 55$ & 1.709325175 & 3.992612492 \\
\hline $8 / 28 / 160: 06$ & 5.041411426 & 16.48174772 \\
\hline $8 / 28 / 160: 12$ & 2.099587198 & 5.913255546 \\
\hline $8 / 28 / 160: 17$ & 1.803568436 & 5.030092487 \\
\hline $8 / 28 / 160: 28$ & 5.619833353 & 10.67579338 \\
\hline $8 / 28 / 161: 56$ & 1.268950267 & 2.018030661 \\
\hline $8 / 28 / 162: 22$ & 4.460006717 & 8.773631497 \\
\hline $8 / 28 / 162: 45$ & 1.258820717 & 3.010358566 \\
\hline $8 / 28 / 163: 19$ & 1.529804085 & 4.049035583 \\
\hline $8 / 28 / 164: 56$ & 1.084224128 & 1.43854853 \\
\hline $8 / 28 / 165: 45$ & 1.276411186 & 2.03967432 \\
\hline $8 / 28 / 169: 23$ & 1.701469929 & 4.692025905 \\
\hline $8 / 28 / 1610: 33$ & 68.98982982 & 140.640138 \\
\hline $8 / 28 / 1611: 14$ & 4.544421112 & 11.17987906 \\
\hline $8 / 28 / 1611: 56$ & 2.522954829 & 8.887402144 \\
\hline $8 / 28 / 1612: 10$ & 2.732283947 & 6.539882812 \\
\hline $8 / 28 / 1613: 02$ & 1.936269947 & 3.163657286 \\
\hline $8 / 28 / 1613: 15$ & 3.748873376 & 8.998144385 \\
\hline $8 / 28 / 1614: 37$ & 2.741670881 & 6.22158355 \\
\hline
\end{tabular}




\begin{tabular}{|c|c|c|}
\hline $8 / 28 / 16$ 15:41 & 1.474562896 & 2.097358881 \\
\hline $8 / 28 / 16$ 16:23 & 4.991661107 & 6.821690651 \\
\hline $8 / 28 / 16$ 17:07 & 1.094400862 & 2.393099829 \\
\hline $8 / 28 / 16$ 20:53 & 2.649108285 & 5.406426368 \\
\hline $8 / 28 / 16$ 23:04 & 20.1692112 & 61.91475827 \\
\hline $8 / 28 / 1623: 50$ & 3.656891445 & 7.26995703 \\
\hline 8/29/16 9:54 & 10.48078433 & 27.03801267 \\
\hline $8 / 30 / 16$ 7:27 & 4.846427014 & 10.56429506 \\
\hline $8 / 31 / 162: 43$ & 58.17318003 & 175.5555189 \\
\hline $8 / 31 / 16$ 6:11 & 43.14496314 & 77.30614251 \\
\hline $8 / 31 / 16$ 20:01 & 0.927585904 & 2.608225679 \\
\hline $9 / 1 / 16$ 15:51 & 1.760307119 & 2.587627706 \\
\hline $9 / 3 / 16$ 19:18 & 5.200882521 & 8.178438155 \\
\hline $9 / 14 / 16$ 16:56 & 1.649958341 & 2.63377859 \\
\hline 9/14/16 19:48 & 3.577561804 & 8.411846575 \\
\hline 9/24/16 18:13 & 1.817530526 & 3.623639837 \\
\hline $9 / 26 / 16$ 19:33 & 1.994728419 & 3.407700273 \\
\hline $9 / 29 / 16$ 19:23 & 1.631463598 & 3.377234436 \\
\hline 9/29/16 21:42 & 1.463794814 & 3.073037916 \\
\hline $10 / 4 / 16$ 6:26 & 1 & 1.831275477 \\
\hline 10/8/16 1:39 & 2.13021034 & 3.479620926 \\
\hline $11 / 5 / 162: 20$ & 2.200116589 & 4.11508994 \\
\hline $11 / 16 / 161: 58$ & 1.562164798 & 3.659260291 \\
\hline $11 / 16 / 16$ 13:18 & 3.044292266 & 7.795313187 \\
\hline
\end{tabular}


Table A4: BBFK Results Part 1

Back azimuths are recorded from each interval of bandpass filters. First, no filter was applied and then two large bandpasses of $2-8 \mathrm{~Hz}$ and $2-6 \mathrm{~Hz}$. Bandpass filters $2 \mathrm{~Hz}$ wide were then applied from $0.01-8 \mathrm{~Hz}$.

\begin{tabular}{|c|c|c|c|c|c|c|c|}
\hline Time & P Wave - No filter & BP 2-8 & BP 2-6 & BP 0.01-2 & BP 2-4 & BP 4-6 & BP 6-8 \\
\hline $8 / 25 / 164: 04$ & 329.7 & 329.7 & 329.7 & 313.5 & 329.7 & 129.4 & 358 \\
\hline $8 / 25 / 16$ 9:27 & 301.3 & 321.6 & 325.6 & 64.72 & 325.6 & 297.3 & 305.4 \\
\hline $8 / 27 / 16$ 17:34 & 325.6 & 325.6 & 325.6 & 309.4 & 329.7 & 305.4 & 301.3 \\
\hline $8 / 27 / 16$ 20:47 & 321.6 & 333.7 & 333.7 & 317.5 & 337.8 & 321.6 & 305.4 \\
\hline $8 / 27 / 1620: 55$ & 224.5 & 297.3 & 297.3 & 216.4 & 317.5 & 297.3 & 97.08 \\
\hline $8 / 27 / 1621: 28$ & 121.3 & 333.7 & 345.8 & 8.09 & 117.3 & 349.9 & 93.03 \\
\hline $8 / 27 / 1621: 34$ & 301.3 & 309.4 & 305.4 & 293.3 & 325.6 & 301.3 & 313.5 \\
\hline $8 / 27 / 1621: 35$ & 0 & 325.6 & 325.6 & 0 & 329.7 & 317.5 & 297.3 \\
\hline $8 / 27 / 1622: 22$ & 121.3 & 329.7 & 333.7 & 0 & 325.6 & 297.3 & 97.08 \\
\hline $8 / 27 / 1622: 35$ & 301.3 & 137.5 & 137.5 & 32.36 & 133.5 & 137.5 & 80.9 \\
\hline $8 / 27 / 1622: 50$ & 137.5 & 137.5 & 133.5 & 0 & 317.5 & 133.5 & 76.85 \\
\hline $8 / 27 / 16$ 23:11 & 121.3 & 232.6 & 232.6 & 0 & 321.6 & 232.6 & 173.9 \\
\hline $8 / 27 / 1623: 38$ & 301.3 & 337.8 & 333.7 & 349.9 & 329.7 & 149.7 & 305.4 \\
\hline $8 / 27 / 16$ 23:43 & 321.6 & 325.6 & 325.6 & 317.5 & 325.6 & 345.8 & 341.8 \\
\hline $8 / 27 / 16$ 23:49 & 358 & 329.7 & 329.7 & 0 & 329.7 & 345.8 & 305.4 \\
\hline $8 / 27 / 1623: 55$ & 121.3 & 325.6 & 325.6 & 20.22 & 325.6 & 20.22 & 80.9 \\
\hline $8 / 28 / 160: 06$ & 325.6 & 329.7 & 329.7 & 0 & 329.7 & 345.8 & 133.5 \\
\hline 8/28/16 0:12 & 121.3 & 325.6 & 325.6 & 0 & 325.6 & 341.8 & 345.8 \\
\hline $8 / 28 / 160: 17$ & 121.3 & 305.4 & 133.5 & 20.22 & 133.5 & 301.3 & 0 \\
\hline $8 / 28 / 16$ 0:28 & 301.3 & 337.8 & 329.7 & 0 & 329.7 & 305.4 & 297.3 \\
\hline $8 / 28 / 161: 56$ & 0 & 329.7 & 329.7 & 0 & 325.6 & 133.5 & 309.4 \\
\hline $8 / 28 / 162: 22$ & 301.3 & 305.4 & 305.4 & 224.5 & 321.6 & 305.4 & 297.3 \\
\hline $8 / 28 / 162: 45$ & 121.3 & 305.4 & 309.4 & 0 & 313.5 & 137.5 & 293.3 \\
\hline $8 / 28 / 163: 19$ & 301.3 & 141.6 & 325.6 & 0 & 325.6 & 137.5 & 349.9 \\
\hline $8 / 28 / 164: 56$ & 121.3 & 317.5 & 313.5 & 297.3 & 321.6 & 305.4 & 301.3 \\
\hline $8 / 28 / 165: 45$ & 121.3 & 4.045 & 157.8 & 113.3 & 285.2 & 157.8 & 8.09 \\
\hline 8/28/16 9:23 & 121.3 & 145.6 & 321.6 & 121.3 & 325.6 & 149.7 & 72.81 \\
\hline $8 / 28 / 16$ 10:33 & 309.4 & 317.5 & 325.6 & 309.4 & 325.6 & 145.6 & 309.4 \\
\hline $8 / 28 / 16$ 11:14 & 301.3 & 301.3 & 325.6 & 212.4 & 325.6 & 232.6 & 301.3 \\
\hline $8 / 28 / 1611: 56$ & 301.3 & 329.7 & 325.6 & 353.9 & 325.6 & 133.5 & 137.5 \\
\hline $8 / 28 / 16$ 12:10 & 121.3 & 329.7 & 329.7 & 0 & 333.7 & 305.4 & 117.3 \\
\hline
\end{tabular}




\begin{tabular}{|c|c|c|c|c|c|c|c|}
\hline $8 / 28 / 16$ 13:02 & 301.3 & 301.3 & 301.3 & 32.36 & 297.3 & 137.5 & 301.3 \\
\hline $8 / 28 / 16$ 13:15 & 301.3 & 141.6 & 137.5 & 264.9 & 317.5 & 137.5 & 224.5 \\
\hline $8 / 28 / 16$ 14:37 & 301.3 & 329.7 & 321.6 & 0 & 325.6 & 305.4 & 297.3 \\
\hline $8 / 28 / 16$ 15:41 & 0 & 137.5 & 137.5 & 0 & 305.4 & 333.7 & 305.4 \\
\hline $8 / 28 / 16$ 16:23 & 301.3 & 301.3 & 301.3 & 240.7 & 329.7 & 297.3 & 301.3 \\
\hline $8 / 28 / 16$ 17:07 & 301.3 & 313.5 & 313.5 & 0 & 313.5 & 137.5 & 345.8 \\
\hline $8 / 28 / 1620: 53$ & 301.3 & 141.6 & 309.4 & 0 & 309.4 & 141.6 & 309.4 \\
\hline $8 / 28 / 1623: 04$ & 149.7 & 149.7 & 317.5 & 321.6 & 329.7 & 145.6 & 68.76 \\
\hline $8 / 28 / 16$ 23:50 & 301.3 & 333.7 & 325.6 & 68.76 & 325.6 & 137.5 & 297.3 \\
\hline 8/29/16 9:54 & 329.7 & 329.7 & 329.7 & 321.6 & 333.7 & 305.4 & 117.3 \\
\hline $8 / 30 / 16$ 7:27 & 301.3 & 333.7 & 333.7 & 28.31 & 333.7 & 333.7 & 141.6 \\
\hline $8 / 31 / 162: 43$ & 313.5 & 313.5 & 313.5 & 321.6 & 321.6 & 137.5 & 321.6 \\
\hline $8 / 31 / 16$ 6:11 & 333.7 & 333.7 & 329.7 & 321.6 & 329.7 & 305.4 & 301.3 \\
\hline $8 / 31 / 16$ 20:01 & 0 & 337.8 & 337.8 & 88.99 & 333.7 & 337.8 & 137.5 \\
\hline 9/1/16 15:51 & 301.3 & 137.5 & 137.5 & 40.45 & 133.5 & 137.5 & 301.3 \\
\hline 9/3/16 19:18 & 301.3 & 309.4 & 309.4 & 64.72 & 313.5 & 305.4 & 133.5 \\
\hline $9 / 14 / 16$ 16:56 & 301.3 & 301.3 & 329.7 & 88.99 & 329.7 & 301.3 & 301.3 \\
\hline 9/14/16 19:48 & 301.3 & 317.5 & 321.6 & 32.36 & 321.6 & 137.5 & 141.6 \\
\hline 9/24/16 18:13 & 301.3 & 329.7 & 325.6 & 345.8 & 325.6 & 297.3 & 301.3 \\
\hline 9/26/16 19:33 & 256.9 & 305.4 & 309.4 & 317.5 & 309.4 & 309.4 & 309.4 \\
\hline $9 / 29 / 16$ 19:23 & 309.4 & 305.4 & 305.4 & 113.3 & 313.5 & 305.4 & 293.3 \\
\hline $9 / 29 / 16$ 21:42 & 188.1 & 317.5 & 321.6 & 0 & 321.6 & 297.3 & 301.3 \\
\hline $10 / 4 / 16$ 6:26 & 341.8 & 305.4 & 305.4 & 24.27 & 313.5 & 305.4 & 301.3 \\
\hline 10/8/16 1:39 & 309.4 & 301.3 & 301.3 & 277.1 & 305.4 & 141.6 & 301.3 \\
\hline $11 / 5 / 162: 20$ & 301.3 & 145.6 & 325.6 & 305.4 & 325.6 & 145.6 & 196.2 \\
\hline $11 / 16 / 161: 58$ & 313.5 & 309.4 & 313.5 & 329.7 & 333.7 & 137.5 & 301.3 \\
\hline $11 / 16 / 1613: 18$ & 337.8 & 309.4 & 309.4 & 349.9 & 329.7 & 309.4 & 301.3 \\
\hline
\end{tabular}


Table A5: BBFK Results Part 2

Back azimuths are recorded for smaller bandpass filters of $1 \mathrm{~Hz}$ iteratively moved from $0.01-8$ Hz. The optimal bandpass is highlighted in green.

\begin{tabular}{|c|c|c|c|c|c|c|c|c|}
\hline Time & BP 0.01-1 & BP 1-2 & BP 2-3 & BP 3-4 & BP 4-5 & BP 5-6 & BP 6-7 & BP 7-8 \\
\hline $8 / 25 / 164: 04$ & 289.2 & 313.5 & 333.7 & 329.7 & 329.7 & 28.31 & 345.8 & 305.4 \\
\hline 8/25/16 9:27 & 64.72 & 301.3 & 329.7 & 325.6 & 84.94 & 24.27 & 345.8 & 0 \\
\hline $8 / 27 / 16$ 17:34 & 309.4 & 305.4 & 329.7 & 329.7 & 125.4 & 24.27 & 301.3 & 305.4 \\
\hline $8 / 27 / 16$ 20:47 & 341.8 & 313.5 & 337.8 & 329.7 & 301.3 & 12.13 & 349.9 & 305.4 \\
\hline $8 / 27 / 16$ 20:55 & 228.5 & 72.81 & 313.5 & 157.8 & 4.045 & 301.3 & 101.1 & 72.81 \\
\hline $8 / 27 / 1621: 28$ & 24.27 & 297.3 & 329.7 & 121.3 & 232.6 & 137.5 & 93.03 & 28.31 \\
\hline $8 / 27 / 1621: 34$ & 293.3 & 313.5 & 329.7 & 141.6 & 129.4 & 301.3 & 97.08 & 20.22 \\
\hline $8 / 27 / 1621: 35$ & 0 & 309.4 & 317.5 & 329.7 & 317.5 & 345.8 & 301.3 & 157.8 \\
\hline $8 / 27 / 1622: 22$ & 0 & 317.5 & 321.6 & 333.7 & 349.9 & 301.3 & 97.08 & 0 \\
\hline $8 / 27 / 1622: 35$ & 36.4 & 313.5 & 317.5 & 333.7 & 309.4 & 301.3 & 137.5 & 80.9 \\
\hline $8 / 27 / 1622: 50$ & 0 & 305.4 & 317.5 & 333.7 & 133.5 & 353.9 & 305.4 & 80.9 \\
\hline $8 / 27 / 16$ 23:11 & 0 & 313.5 & 36.4 & 121.3 & 232.6 & 293.3 & 178 & 313.5 \\
\hline $8 / 27 / 16$ 23:38 & 24.27 & 313.5 & 329.7 & 325.6 & 337.8 & 244.7 & 169.9 & 305.4 \\
\hline $8 / 27 / 16$ 23:43 & 333.7 & 317.5 & 321.6 & 333.7 & 345.8 & 12.13 & 129.4 & 16.18 \\
\hline $8 / 27 / 16$ 23:49 & 0 & 321.6 & 329.7 & 341.8 & 341.8 & 337.8 & 345.8 & 149.7 \\
\hline $8 / 27 / 16$ 23:55 & 16.18 & 317.5 & 321.6 & 145.6 & 32.36 & 20.22 & 321.6 & 200.2 \\
\hline $8 / 28 / 16$ 0:06 & 184 & 317.5 & 325.6 & 337.8 & 345.8 & 16.18 & 129.4 & 141.6 \\
\hline $8 / 28 / 16$ 0:12 & 0 & 317.5 & 321.6 & 141.6 & 345.8 & 329.7 & 345.8 & 93.03 \\
\hline $8 / 28 / 16$ 0:17 & 32.36 & 313.5 & 321.6 & 337.8 & 301.3 & 244.7 & 141.6 & 0 \\
\hline $8 / 28 / 160: 28$ & 48.54 & 317.5 & 333.7 & 325.6 & 329.7 & 305.4 & 297.3 & 28.31 \\
\hline $8 / 28 / 161: 56$ & 0 & 305.4 & 325.6 & 333.7 & 321.6 & 145.6 & 133.5 & 309.4 \\
\hline $8 / 28 / 162: 22$ & 220.4 & 317.5 & 40.45 & 305.4 & 141.6 & 20.22 & 64.72 & 188.1 \\
\hline $8 / 28 / 162: 45$ & 0 & 256.9 & 305.4 & 317.5 & 133.5 & 297.3 & 337.8 & 289.2 \\
\hline 8/28/16 3:19 & 121.3 & 313.5 & 325.6 & 329.7 & 137.5 & 297.3 & 141.6 & 349.9 \\
\hline $8 / 28 / 164: 56$ & 301.3 & 313.5 & 321.6 & 321.6 & 141.6 & 153.7 & 321.6 & 305.4 \\
\hline $8 / 28 / 165: 45$ & 113.3 & 52.58 & 293.3 & 285.2 & 224.5 & 133.5 & 196.2 & 0 \\
\hline $8 / 28 / 16$ 9:23 & 121.3 & 192.1 & 325.6 & 329.7 & 149.7 & 149.7 & 244.7 & 72.81 \\
\hline $8 / 28 / 16$ 10:33 & 309.4 & 309.4 & 329.7 & 325.6 & 337.8 & 28.31 & 137.5 & 12.13 \\
\hline $8 / 28 / 16$ 11:14 & 208.3 & 317.5 & 329.7 & 325.6 & 329.7 & 297.3 & 133.5 & 145.6 \\
\hline $8 / 28 / 16$ 11:56 & 358 & 321.6 & 325.6 & 325.6 & 133.5 & 8.09 & 145.6 & 84.94 \\
\hline $8 / 28 / 16$ 12:10 & 0 & 305.4 & 333.7 & 137.5 & 325.6 & 309.4 & 353.9 & 0 \\
\hline 8/28/16 13:02 & 36.4 & 305.4 & 297.3 & 216.4 & 232.6 & 301.3 & 337.8 & 224.5 \\
\hline 8/28/16 13:15 & 244.7 & 305.4 & 301.3 & 317.5 & 232.6 & 301.3 & 337.8 & 224.5 \\
\hline
\end{tabular}




\begin{tabular}{|l|r|r|r|r|r|r|r|r|}
\hline $8 / 28 / 1614: 37$ & 0 & 309.4 & 333.7 & 321.6 & 317.5 & 301.3 & 305.4 & 341.8 \\
\hline $8 / 28 / 1615: 41$ & 0 & 317.5 & 301.3 & 309.4 & 337.8 & 285.2 & 305.4 & 4.045 \\
\hline $8 / 28 / 1616: 23$ & 216.4 & 325.6 & 333.7 & 301.3 & 329.7 & 297.3 & 305.4 & 301.3 \\
\hline $8 / 28 / 1617: 07$ & 0 & 301.3 & 208.3 & 329.7 & 313.5 & 141.6 & 145.6 & 297.3 \\
\hline $8 / 28 / 1620: 53$ & 0 & 313.5 & 305.4 & 321.6 & 141.6 & 289.2 & 305.4 & 309.4 \\
\hline $8 / 28 / 1623: 04$ & 321.6 & 317.5 & 325.6 & 329.7 & 297.3 & 101.1 & 145.6 & 68.76 \\
\hline $8 / 28 / 1623: 50$ & 68.76 & 309.4 & 329.7 & 325.6 & 333.7 & 301.3 & 297.3 & 184 \\
\hline $8 / 29 / 169: 54$ & 273 & 309.4 & 333.7 & 137.5 & 325.6 & 305.4 & 97.08 & 180 \\
\hline $8 / 30 / 167: 27$ & 28.31 & 317.5 & 333.7 & 329.7 & 333.7 & 305.4 & 305.4 & 145.6 \\
\hline $8 / 31 / 162: 43$ & 313.5 & 321.6 & 325.6 & 317.5 & 137.5 & 309.4 & 321.6 & 321.6 \\
\hline $8 / 31 / 166: 11$ & 321.6 & 317.5 & 333.7 & 321.6 & 329.7 & 301.3 & 297.3 & 169.9 \\
\hline $8 / 31 / 1620: 01$ & 93.03 & 309.4 & 333.7 & 337.8 & 337.8 & 305.4 & 317.5 & 309.4 \\
\hline $9 / 1 / 1615: 51$ & 40.45 & 184 & 309.4 & 137.5 & 309.4 & 301.3 & 137.5 & 84.94 \\
\hline $9 / 3 / 1619: 18$ & 64.72 & 321.6 & 313.5 & 309.4 & 20.22 & 301.3 & 133.5 & 349.9 \\
\hline $9 / 14 / 1616: 56$ & 93.03 & 337.8 & 325.6 & 329.7 & 349.9 & 301.3 & 256.9 & 301.3 \\
\hline $9 / 14 / 1619: 48$ & 32.36 & 309.4 & 329.7 & 317.5 & 317.5 & 301.3 & 301.3 & 52.58 \\
\hline $9 / 24 / 1618: 13$ & 341.8 & 317.5 & 325.6 & 317.5 & 333.7 & 293.3 & 301.3 & 169.9 \\
\hline $9 / 26 / 1619: 33$ & 317.5 & 321.6 & 313.5 & 305.4 & 137.5 & 309.4 & 80.9 & 289.2 \\
\hline $9 / 29 / 1619: 23$ & 117.3 & 309.4 & 317.5 & 305.4 & 305.4 & 305.4 & 305.4 & 289.2 \\
\hline $9 / 29 / 1621: 42$ & 0 & 232.6 & 321.6 & 325.6 & 329.7 & 297.3 & 157.8 & 157.8 \\
\hline $10 / 4 / 166: 26$ & 28.31 & 313.5 & 317.5 & 309.4 & 309.4 & 305.4 & 305.4 & 4.045 \\
\hline $10 / 8 / 161: 39$ & 277.1 & 313.5 & 301.3 & 125.4 & 301.3 & 141.6 & 301.3 & 297.3 \\
\hline $11 / 5 / 162: 20$ & 305.4 & 313.5 & 325.6 & 325.6 & 145.6 & 24.27 & 341.8 & 196.2 \\
\hline $11 / 16 / 161: 58$ & 337.8 & 317.5 & 337.8 & 305.4 & 133.5 & 137.5 & 145.6 & 301.3 \\
\hline $11 / 16 / 1613: 18$ & 349.9 & 317.5 & 333.7 & 313.5 & 133.5 & 141.6 & 145.6 & 297.3 \\
\hline
\end{tabular}




\section{Curriculum Vita}

In 2012, Emily Graves graduated from Munising High School and began pursuing a bachelor's degree in geology at Lake Superior State University. She graduated in 2016 and started a master's degree in geophysics at the University of Texas at El Paso. For eight months she interned at Los Alamos National Laboratory conducting research for her thesis in earthquake location integrity. While taking classes at the University of Texas at El Paso, she taught introductory geology laboratories and graded for introductory geology classes. Her research poster entitled, "Exploring a Well-located Seismic Sequence Near Jackson, Wyoming: Application of Array Methods and Waveform Cross-correlation" was presented at the American Geophysical Union meeting in Washington D.C. in December 2018.

She will graduate in December 2018 with a master's degree in geophysics and begin a Ph.D. in geophysics and geodesy at New Mexico Institute of Mining and Technology. She can be reached via the following email: egraves@miners.utep.edu. 